\title{
FRANCISCO DE GOYA: TRES CUADROS, TRES ÉPOCAS
}

\author{
POR \\ JOSÉ MANUEL ARNAIZ \\ Association of Art Historians
}

\begin{abstract}
The author publishes three works in his opinion belonging to three periods of Goya's activity: The first one The Death of San Francisco Javier is the definitive version based on the "bozetto" now in the Zaragoza Museum which derives from a drawing and canvass by the italian painter Bertucci. The second is The Portrait of Child Pedro Jordan de Urries, heir of the Marquesado de Ayerbe, as first born of one of the most aristocratic and rich families of Zaragoza. The third work is a sketch for The Tribunal of the Inquisición now in the Accademy of San Fernando with remarkable diferences, which raises again the problem of the series of small panels in the Munich Museum. The author includes interesting letters adressed by Matheron to Valentin Carderera asking information about Goya, and reproduce the original text of Goya's letter to Zapater dated of 15th. April 1777, until now homeless.
\end{abstract}

Conocidas son la dificultades existentes para la datación de las obras de Goya en función de su estilo y no solo por su lógica evolución, sino básicamente por la notoria diferencia expresiva empleada por el maestro dependiendo de por quien o para quien era hecho el encargo. Basta para mantener esta afirmación el contenido de algunas de las cartas milagrosamente salvadas de su correspondencia con su íntimo amigo Martín Zapater. Por ejemplo cuando le dice «Me abía yo establecido un modo de vida enbidiable; ya no acía antesala alguna, el que quería algo mío me buscaba; yo me acía desear mas y si no era personage muy elebado o con empeño de algun amigo no trabajaba nada para nadie; y por lo mismo que yo me acía tan preciso no me dejaban (ni aun me dejan) que no se como he de cumplir...» ${ }^{1} \mathrm{O}$ al recordar aquella frase de su hijo Xavier cuando en la biografía de su padre que le encargó la Real Academia de San Fernando especificaba que «Fue bastante feliz con los retratos y aquellos que hizo en una sola sesión han merecido más general aprobación» ${ }^{2}$.

Es fácil suponer que estas idas y venidas estilísticas de Goya puestas a disposición de la clientela, hayan provocado el que en los numerosos intentos de catalogación de su obra se encuentren períodos creídos de una abundante actividad, dada la semejanza técnica de los cuadros entre sí, alternados con otros largos tiempos — a veces años- de vacío casi absoluto ${ }^{3}$ y que

\footnotetext{
${ }^{1}$ Cañellas, A.: Diplomatario de Goya. Zaragoza, 1981, doc. 111, pág. 270.

2 Ibídem: Doc. CLXXXVII, pág. 519. La cita como publicada por Beroqui, aún cuando esta está compuesta por las dos biografías hechas por Xavier (Canellas CLXXXVI y CLXXVII), y cuya nota manuscrita fue dada por Xavier a Carderera, encontrada por Beroqui en el Prado y publicada por él en Archivo Español de Arte y Arqueología, T. III, 1927, págs. 99100. La que Beroqui dice publicada por Calleja en 1924, es un resumen.
} 
tal vez debiera ser ocupado con obras datadas por los investigadores erróneamente por tal causa. Todo ello origina un desconcierto a duras penas solventado por las fechadas por el propio pintor o por indubitables documentos. Nada puede extrañar pues, la satisfacción que produce el hallazgo de nuevos cuadros del pintor susceptibles de ser fechados con una razonable seguridad y que de este modo coadyuven en el futuro a obtener una cada vez más afinada seriación cronológica que permita la depuración de obras apócrifas que su catálogo necesita.

\section{La muerte de San Francisco Javier}

Existe un pequeño cuadrito de Goya adquirido por la Real Academia de Bellas Artes de San Luis en 1927 de Manuela Lucientes, descendiente de un tío carnal del pintor, cuyo tema fue identificado correctamente en $1954^{4}$ como representación de La muerte de San Francisco Javier (Fig. 1) ocurrida en la isla de Shangxuan a la vista de Cantón la madrugada del 3 de diciembre de 1552 y que había figurado hasta entonces como Invención del cuerpo de Santiago ${ }^{5}$.

El cuadro, que como su pareja de la misma procedencia que representa La Virgen del Pilar, han sido discutidos en algunas ocasiones como obra de Goya, han visto confirmada su autenticidad - al igual que algunas otras obras juveniles del pintor - con la adquisición y publicación por el Museo del Prado del poco afortunadamente llamado Cuaderno italiano ${ }^{6}$ en el que aparecen tres dibujos directamente relacionables con ambos cuadros, de los cuales dos específicamente con La muerte de San Francisco Javier ${ }^{7}$ (Figs. 2 y 3), que por otra parte se ha conectado con escaso fundamento con un grabado sobre dibujo de Geminiani y muy razonablemente con uno de los dibujos que existen en la Academia de San Luis formando parte de la colección adquirida y traída a España para servir de modelos a los alumnos por Vicente Pignatelli probablemente entre 1754 y 1759, fecha del traslado del procer aragonés a Madrid ${ }^{8}$. Se trata del atribuido a Niccolo Bertuzzi, o Bertucci conocido también como «Niccolo de Ancona» por el lugar de su nacimiento cuya fecha se ignora y fallecido en Bolonia en $1777^{9}$ (Fig. 4) y del que existe un posible boceto que incluso tal vez sea el cuadro final ${ }^{10}$ (Fig. 5).

Pues bien, Goya, asistente a las clases de la incipiente Academia zaragozana conoció sin duda al igual que sus condiscípulos, este dibujo que aún se conserva en la docta corporación y sobre el que hubo de basar su cuadrito del Museo de Bellas Artes, cuya composición debió pre-

\footnotetext{
${ }^{3}$ Para una relación puramente indicativa y limitada a su primera época he recurrido a los más divulgados textos de la bibliografía goyesca, frondoso árbol que con frecuencia impide ver el bosque. No habiendo seguridad en ninguno de ellos, el interesado podría realizar su propia lista con igual o muy parecido resultado al que en esta nota presento. Nacido en 1746, tras su viaje a Italia y hasta su instalación en Madrid en 1774 - es decir a sus 28 años - se vienen admitiendo unas 50 pinturas, incluyendo el fresco del coreto y las del Aula Dei, todas ellas de grandes dimensiones, siendo el resto de pequeño formato, cantidad a todas luces escasa para un temperamento y fertilidad como las de Goya.

${ }^{4}$ Milicua, J.: «Aportaciones al Goya joven», en Paragone, n. ${ }^{\circ}$ 53, 1954, pág. 59, nota 2.

${ }^{5}$ Exposición. Goya 1746-1828. Realidad e Imagen. Zaragoza, 1996, pág. 72. Se dice que mantuvo la errónea identificación en los catálogos del Museo hasta 1975. Debe tenerse en cuenta que cuando no se especifica el nombre del autor en el texto, las notas y los pies de las figuras, se trata de obras de Francisco de Goya, en opinión del autor.

6 VV.AA.: El cuaderno italiano. 1770-1786. Los orígenes del arte de Goya. Madrid, 1994. Abarca anotaciones desde 1770 (supuesta llegada a Italia) hasta 1786 (15 años después de su regreso a España).

7 Ibídem: pág. 135, anv. . y 86 rec. ${ }^{\circ}$. Respecto a este último, la transcripción anotada por Manuela Mena sugiere que se trate de un estudio para un Sueño de San José quizá relacionado con las pinturas del Aula Dei, lo que a la vista de la iconografía parece no solo poco probable como veremos, sino que ninguna noticia existe sobre una composición de tal tema en la Cartuja.

${ }^{8}$ Ansón Navarro, A.: «Historia y caracteres del fondo de dibujos de la Real Academia de San Luis», en Goya y sus inicios académicos, Zaragoza, 1996, pág. XLIV.

${ }^{9}$ Ibídem, págs. 112 y 114-115.

${ }^{10}$ Óleo sobre lienzo, $0,44 \times 0,33 \mathrm{~m}$, colección particular.
} 


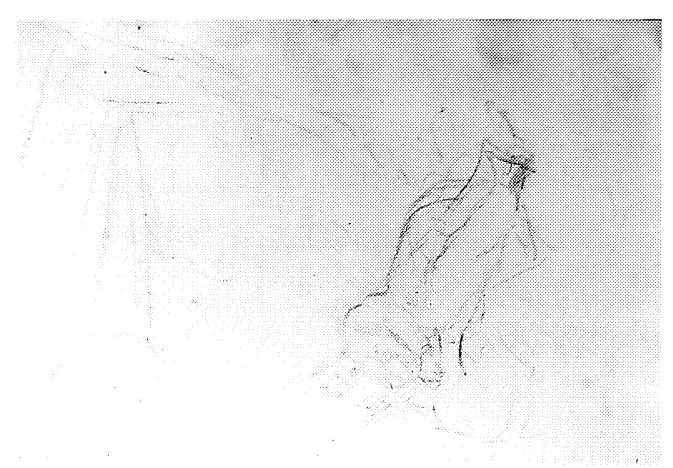

4

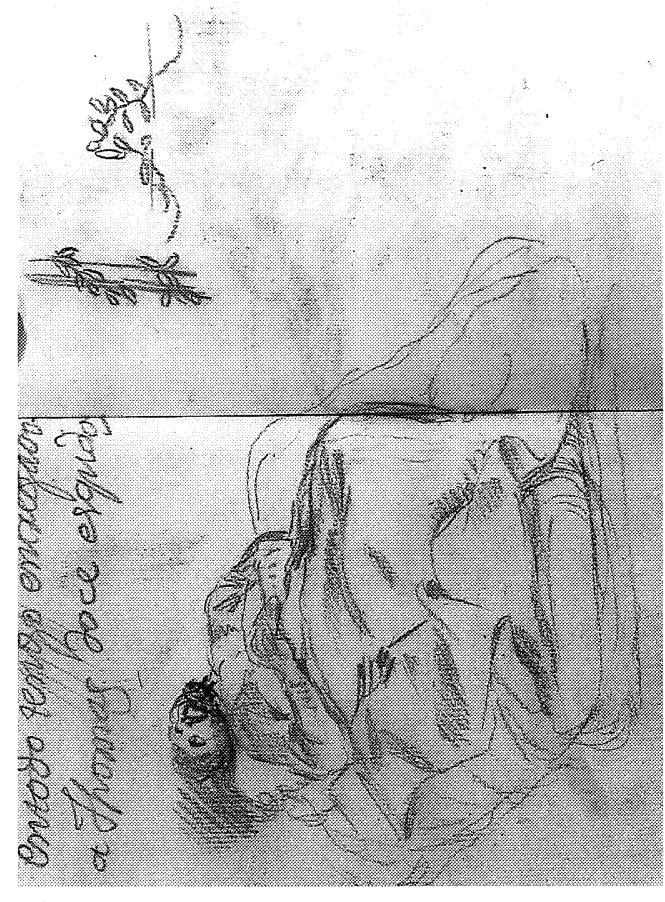

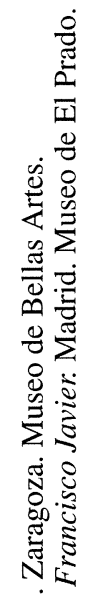

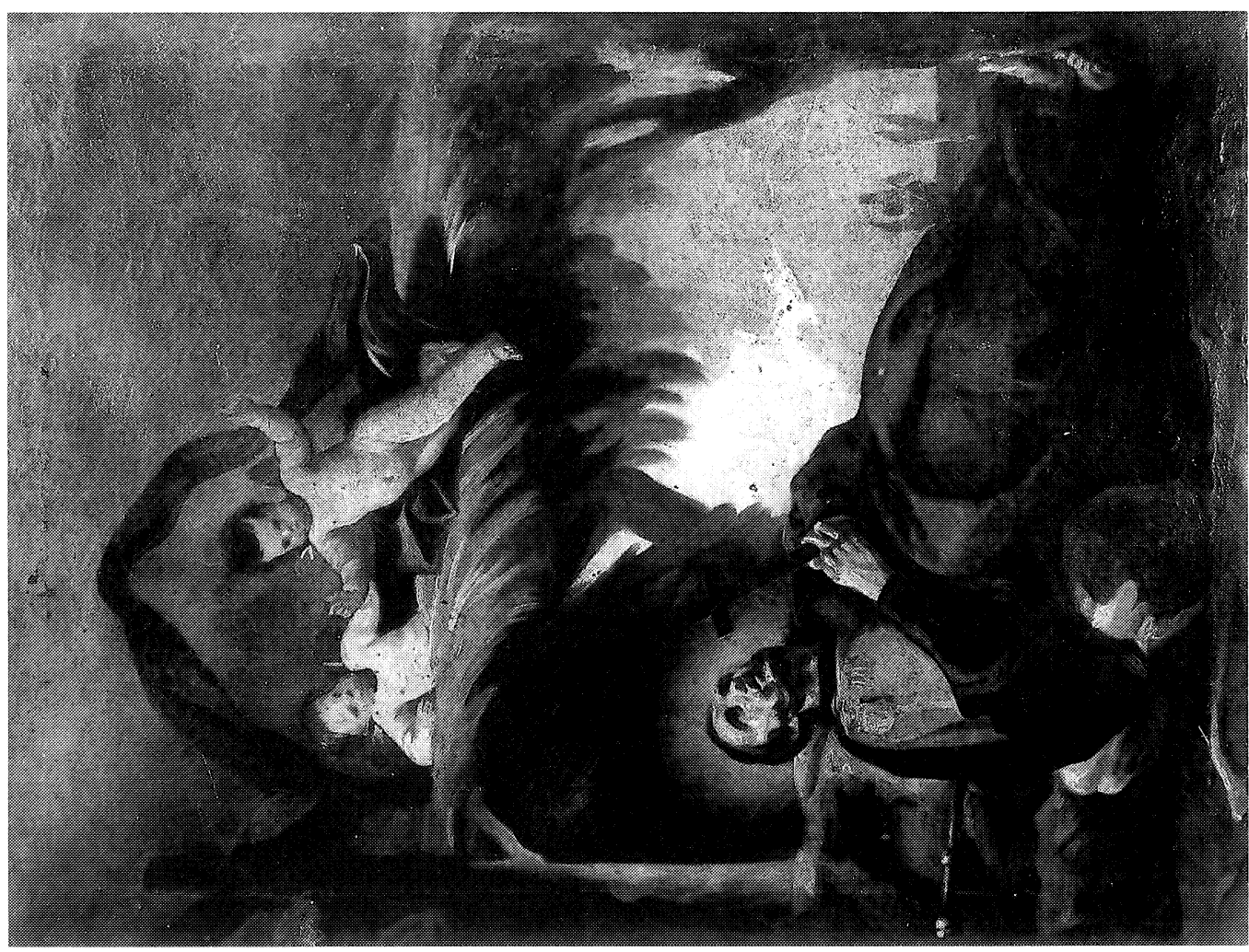

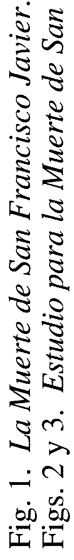



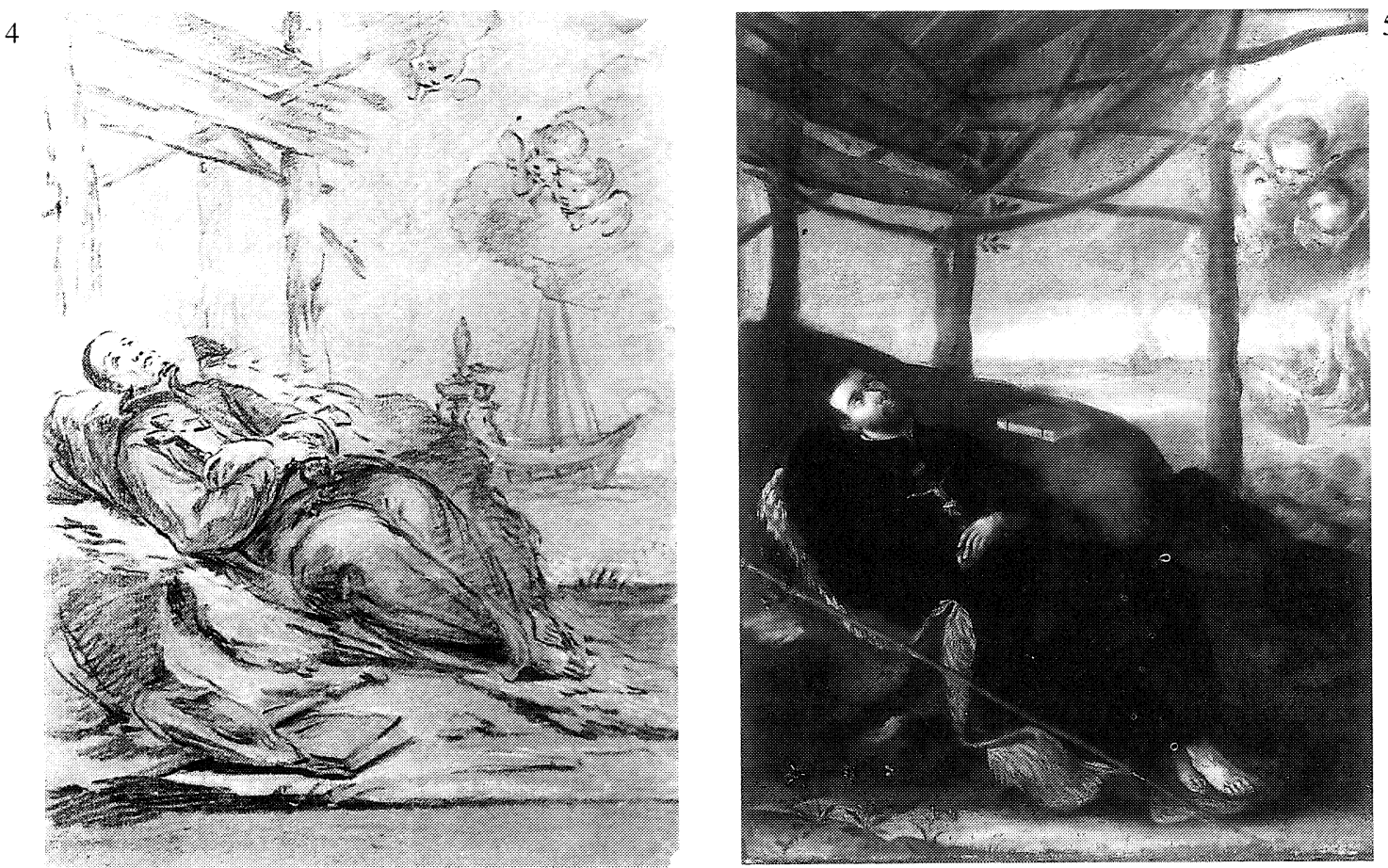

6

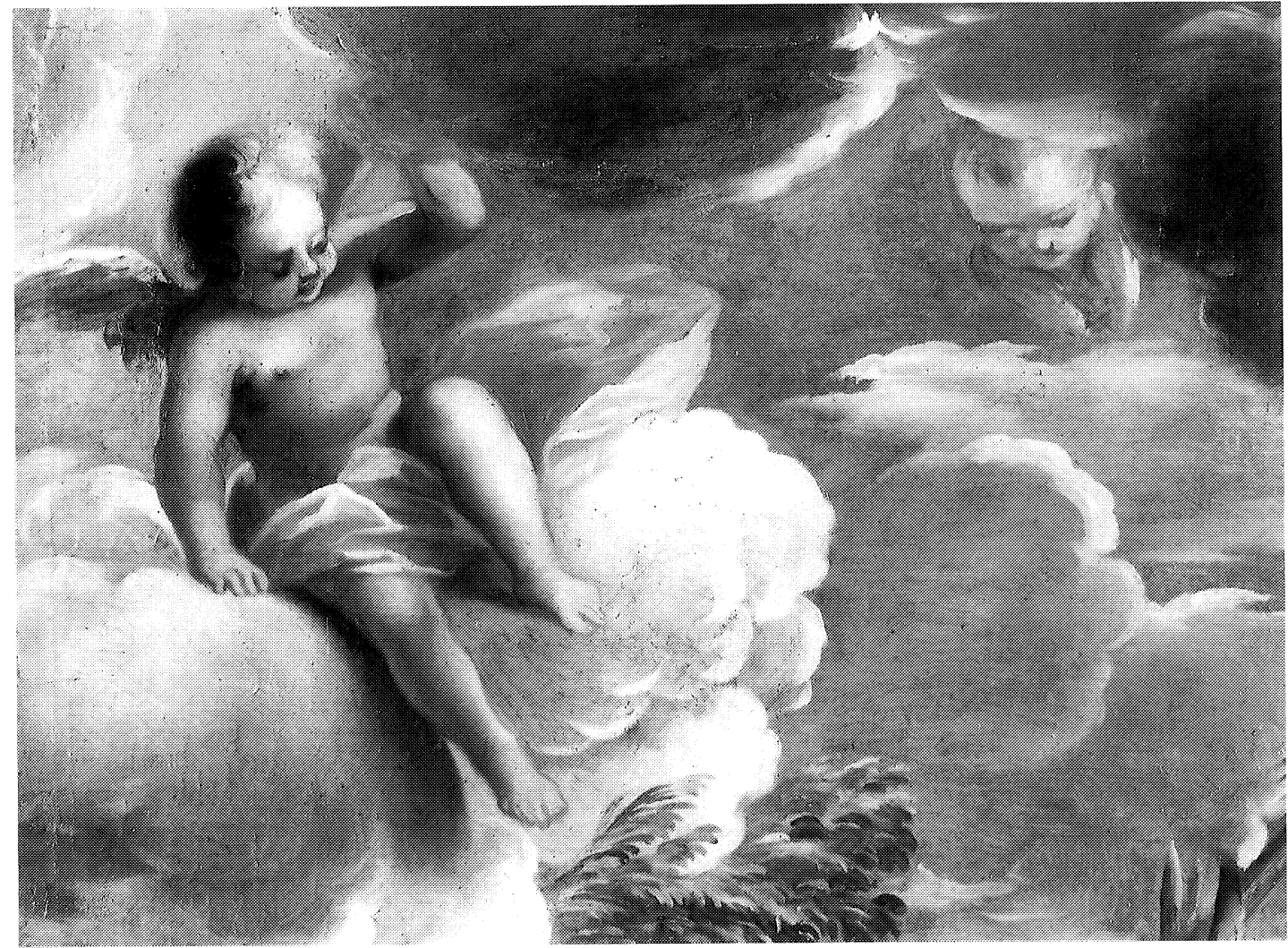

Fig. 4. Estudio para la Muerte de San Francisco Javier, por Niccolo Bertucci. Zaragoza. Museo de Bellas Artes. Fig. 5. La Muerte de San Francisco Javier, por Niccolo Bertucci, col. particular.

Fig. 6. La Muerte de San Francisco Javier, detalle, col. particular. 
ocuparle bastante como demuestran los dibujos del Cuaderno italiano. Si bien en el primero de ellos (Fig. 2) el Santo no ha fallecido, sino que inclina su cuerpo en contemplación del crucifijo y viéndose solamente indicado el sombrajo, en el segundo (Fig. 3) la figura yacente es ya la de un cadáver, pero en sus entrecruzadas manos no figura el crucifijo - lo que quizá ha permitido pensar, erróneamente en mi opinión, que podría tratarse de un estudio para una muerte de San José ${ }^{11}$ — con el que sí le vemos en el cuadro de Zaragoza, que en todo caso es más próximo al dibujo de Bertucci.

Hace poco más de un año apareció un interesantísimo cuadro, que una vez desnudado de las sucesivas capas de suciedad y barnices oxidados que le recubrían, ha mostrado todo su esplendor $^{12}$ (Figs. 7-8). Es prácticamente la misma composición que la del cuadrito de Zaragoza invertida derecha-izquierda. San Francisco Javier aún vivo, con los ojos elevados en muda súplica al cielo, pequeños barcos en el horizonte, en ambos la escena encuadrada por unos árboles y muy parecido el sombrajo, siendo la variante más significativa el aspecto de su rostro alejado desde luego del cadavérico que presenta el de Zaragoza y otra, aunque de escasa importancia, la de que el Santo tiene el crucifijo sobre el pecho en lugar de sostenido entre sus manos, siguiendo en esto el dibujo de Bertucci.

Claro que la composición al ser en esta ocasión mucho más amplia, presenta un dilatado horizonte marino, que en el cuadro del italiano o en el de Zaragoza es solo una sugerencia secundaria. También los ángeles comparten su inspiración entre estos dos: uno sobrevuela sobre una nube como en el de Goya y el otro se ve reducido a una simple cabeza como en el de Niccolo (Fig. 6).

Son estas coincidencias tan evidentes, que obligan a traer a la memoria la frase inglesa «una vez coincidencia, dos veces no es coincidencia».

El cuadro está cuidadosamente realizado acusando ya un concepto plenamente neoclasicista, al igual que ocurre con la versión definitiva del Aníbal pasando los Alpes en relación con su boceto $^{13}$, aunque presentando evidentes estilemas de Goya: Las larguísimas pinceladas tanto negras como blancas, aplicadas estas en veladuras tan sutiles que la fotografía tiene serias dificultades para manifestarlas con las que se han definido el hábito, las arrugas del tejido y los pliegues necesarios para amoldarlo a las formas del cuerpo del Santo. Alguna de aquellas cargada de esa materia negra tan característica, llega a medir ¡más de 30 centímetros; Así mismo las fisonomías de los ángeles, la fuerza que emana de todo el conjunto, sugieren su ejecución goyesca.

¿Cuando pudo realizar Francisco de Goya esta pintura? Los dibujos del Cuaderno italiano, que evidentemente comienza entre 1769 y 1770, es decir en su viaje a Italia, indican la fecha «post quem». La semejanza de sus angelotes con los que aparecen en el boceto de la Adoración del nombre de Dios, con que decoró el «coreto» del templo del Pilar en Zaragoza o con los que vemos en su Virgen del Pilar pareja del boceto de La muerte de San Francisco Javier, parece indicar que el cuadro definitivo debió ser pintado hacia 1771 poco después de su regreso de aquel viaje.

Cierto que esta datación aconseja modificar la atribuida a ambos bocetos —el actual hallazgo hace presumir la existencia de una versión definitiva de su pareja la Pilarica supérstite o noy que vienen siendo situados hacia 1775-1778 por Gudiol ${ }^{14}$, entre 1775 y 1780 por Gassier-Wilson ${ }^{15}$ y más reciente y acertadamente entre 1771 y 1775 , por Wilson-Bareau ${ }^{16}$, siendo la primera de estas últimas o su inmediato entorno la que me parece más acertada.

\footnotetext{
11 Vid. nota 7

12 Óleo sobre lienzo, $1,062 \times 0,780 \mathrm{~m}$, colección particular.

${ }_{13}$ Respecto al boceto vid. Arnaiz, J. M. y Buendía, R.: «Aportaciones al joven Goya», en Archivo Español de Arte, n. ${ }^{\circ} 226,1984$. Respecto al cuadro final vid. nota 6, págs. 40-52, «El Aníbal de Goya reencontrado», por Jesús Urrea.

${ }^{14}$ Gudiol, J.: Goya, Barcelona, 1970 - en adelante G-, n. ${ }^{\circ} 112-113$.

${ }_{15}$ Gassier-Wilson: Vie et oevre de Francisco Goya, Friburgo, 1970 - en adelante G-W_, n. 230.

${ }^{16}$ Wilson-Bareau, J.: «El capricho y la invención», en Goya. El capricho y la invención, Madrid, 1993, págs. 112-115.
} 


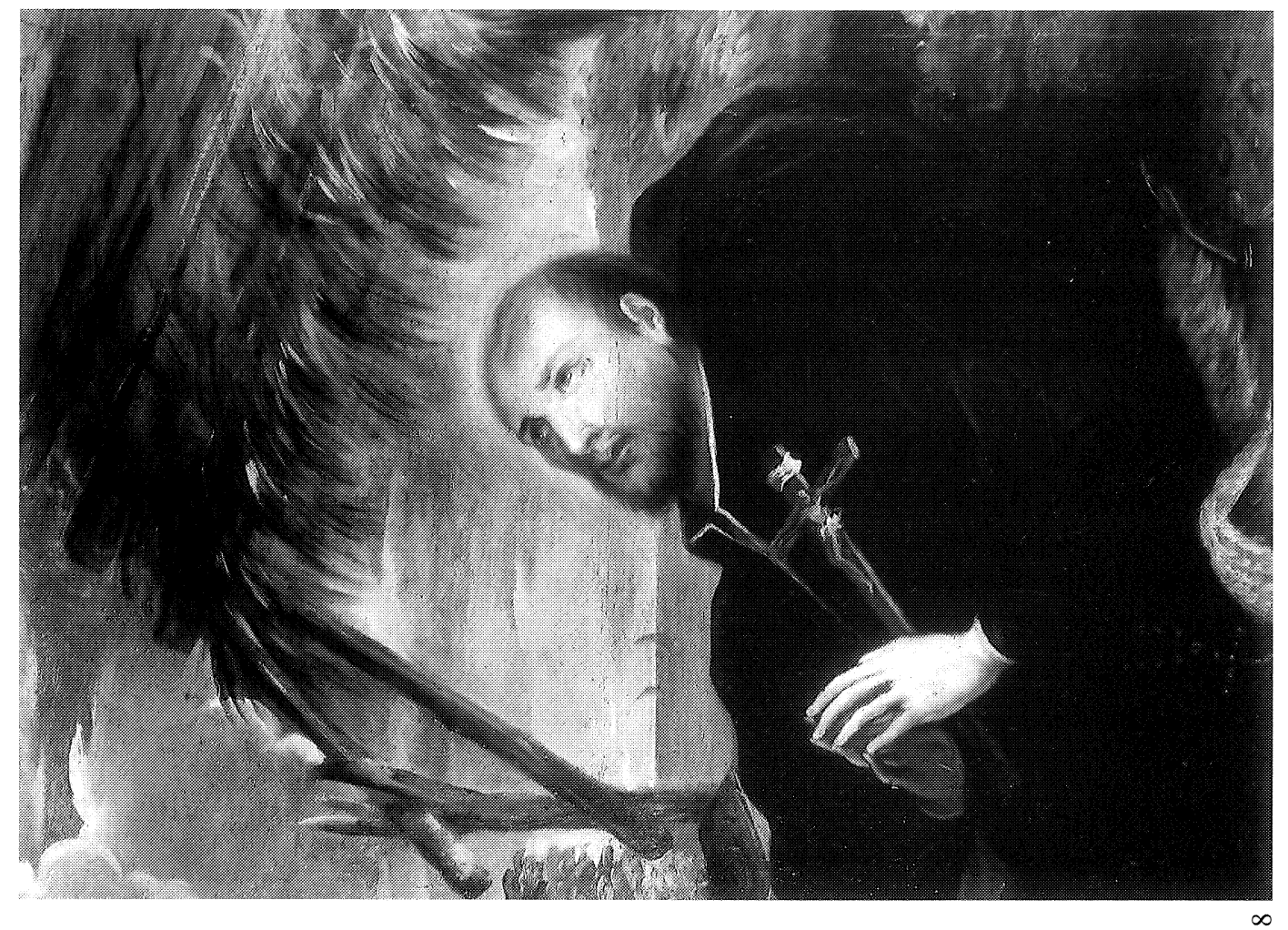

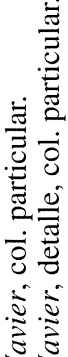

r

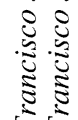

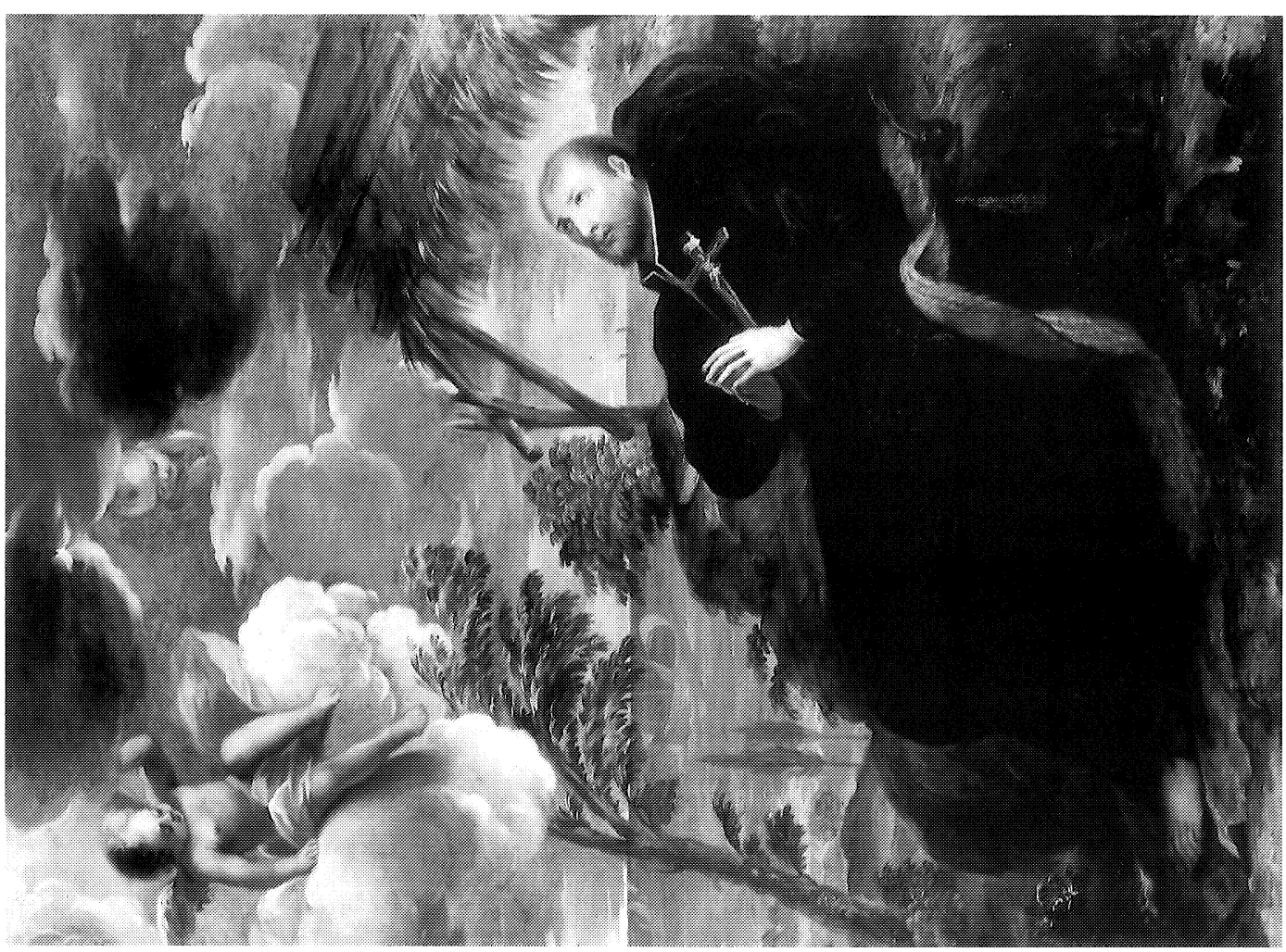

吾

जั

ะะ

ปับ

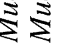

2.2

$\therefore \infty$

注定 
Otra hipótesis que, al menos como elemento de trabajo, cabe emitir es sobre quien pudo ser el comitente. Habida cuenta de la reciente promulgación en 1767 del edicto de expulsión de la Compañía de Jesús de los Reinos de España, debió ser encargado el cuadro no solo por algún cliente influyente, lo que obligó a Goya a trabajar con estudios y diversos tanteos previos, sino también próximo o conectado con los jesuitas, para quienes San Francisco Javier era recuerdo permanente de los hermanos muertos lejos de su tierra.

Cabe traer a colación mi tesis ya expuesta hace años ${ }^{17}$ sobre la probable protección dispensada al pintor por los hermanos Pignatelli, hijos del Conde de Fuentes, Señor de Fuendetodos el pueblecito natal de Goya, de los cuales uno fue precisamente el ilustrado Vicente, quien como hemos visto donó una colección de dibujos a la Escuela de Dibujo de Zaragoza, más tarde Academia de San Luis. Otro, Ramón, Canónigo del Pilar para cuyo templo Goya pintó el «coreto» y finalmente José, con el tiempo Beato José de Pignatelli, jesuita y considerado como el refundador de la Compañía tras su supresión y que muy probablemente fue aquel «fraile» al que los primeros biógrafos del pintor atribuyeron haber sido el descubridor de las dotes artísticas del joven pintor ${ }^{18}$. Hay que recordar así mismo como la Compañía estuvo presente en la obra del joven y no tan joven Goya, con importantes encargos ${ }^{19}$. Nada tendría de raro que alguno de los Pignatelli o el mismo José, estuviera detrás del encargo de La muerte de San Francisco Javier.

\section{Retrato de Pedro Jordán de Urríes}

Tal y como reza la cartela que se halla en el copete que remata el espléndido marco, estamos ante el retrato del mayorazgo de una de las más importantes familias aragonesas del siglo XVIII: el «Ilm ${ }^{\circ}$ Sr. Dn. Pedro Jordan Maria D. Urries y Fuenbuena infante D N ${ }^{a}$. Señora Nacio en 13 D Octubre D 1770» (Fig. 9). Este niño, que representa unos 6 u 8 años de edad, acababa de suceder a su padre D. Pedro Jordán de Urríes y Pignatelli — de nuevo la familia PignatelliViceprotector de la Junta Preparatoria de la Academia Zaragozana en cuyo palacio estuvo instalada y fallecido precisamente en 1770 y de Dña. María Ramona Fuenbuena y Monserrat, Marqueses de Ayerbe y naturales ambos de Zaragoza ${ }^{20}$. Retratado con el hábito de Infante de la Virgen del Pilar, cuya imagen vemos a la izquierda del espectador y luciendo al cuello su medalla, entró desde muy joven al servicio como paje del entonces Príncipe de Asturias y más tarde Fernando VII, a quien acompañó como Gentilhombre y segundo Mayordomo a su exilio en Valençay, de donde fue expulsado en 1809 por Napoleón a causa de sus actividades a favor de su Señor. Pasó a Bayona y desde allí a Pamplona y Sevilla, donde otorgó testamento por estar «próximo a entrar en campaña ${ }^{21}$. Casado en primeras nupcias con María Nicolasa de Palafox y Silva $^{22}$ y en segundas con María Juana de Dios Bucarelli y Bucarelli, el Marqués de Ayerbe, de Rubí, y de Lierta, Barón de Sánchez de Toledo y Torrellas, las dotes concedidas a ambas señoras dejan constancia de su excelente y holgadísima situación económica así como de su gene-

17 Arnaiz, J. M.: «Goya, Pignatelli y Azara», en Archivo Español de Arte, 1988, LXI, págs. 131-140.

${ }^{18}$ Esta hipótesis de trabajo expuesta en el artículo precedente va abriéndose camino y ganando adeptos. Vid. Ansón, A.: Goya en Aragón, Zaragoza, 1995, págs. 37, 45, 48, 73 nota 150, 74 nota 153.

19 Vid. nota 17.

${ }^{20}$ Archivo Histórico Nacional, Órdenes, Calatrava, exp. 76 moderno, fol. 45.

${ }^{21}$ Ibidem. Se dice que en la notaría de Manuel Gil y Burillo hay un «cuaderno suelto sin cubiertas, compuesto de 44 folios y en ellos las diligencias de muerte, apertura y protocolización del testamento de D. Pedro Jordán Maria de Urries y Fuenbuena». El testamento está en el f. ${ }^{\circ} 35$. Efectivamente, en los protocolos de tal Archivero y Notario se encuentran además numerosos documentos referentes al personaje y su testamentaría, bastante complicada por cierto, por ejemplo los n. ${ }^{\circ} 5.593,5.595$ y 5.588

22 Parroquia de San Martín, 21 de septiembre de 1789. 


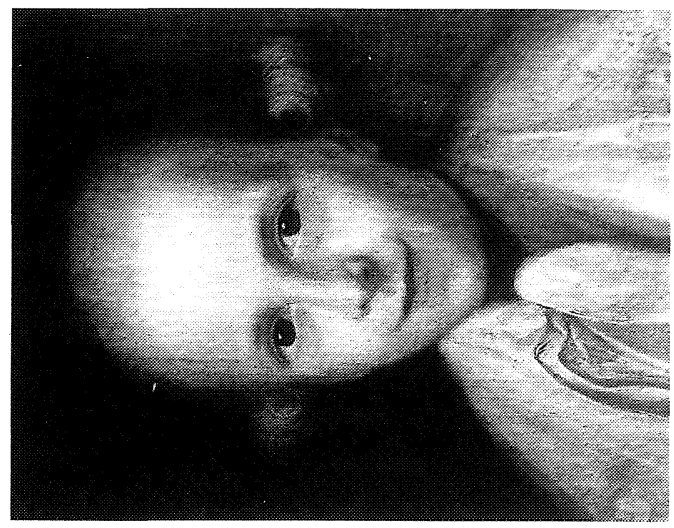

으

$a$

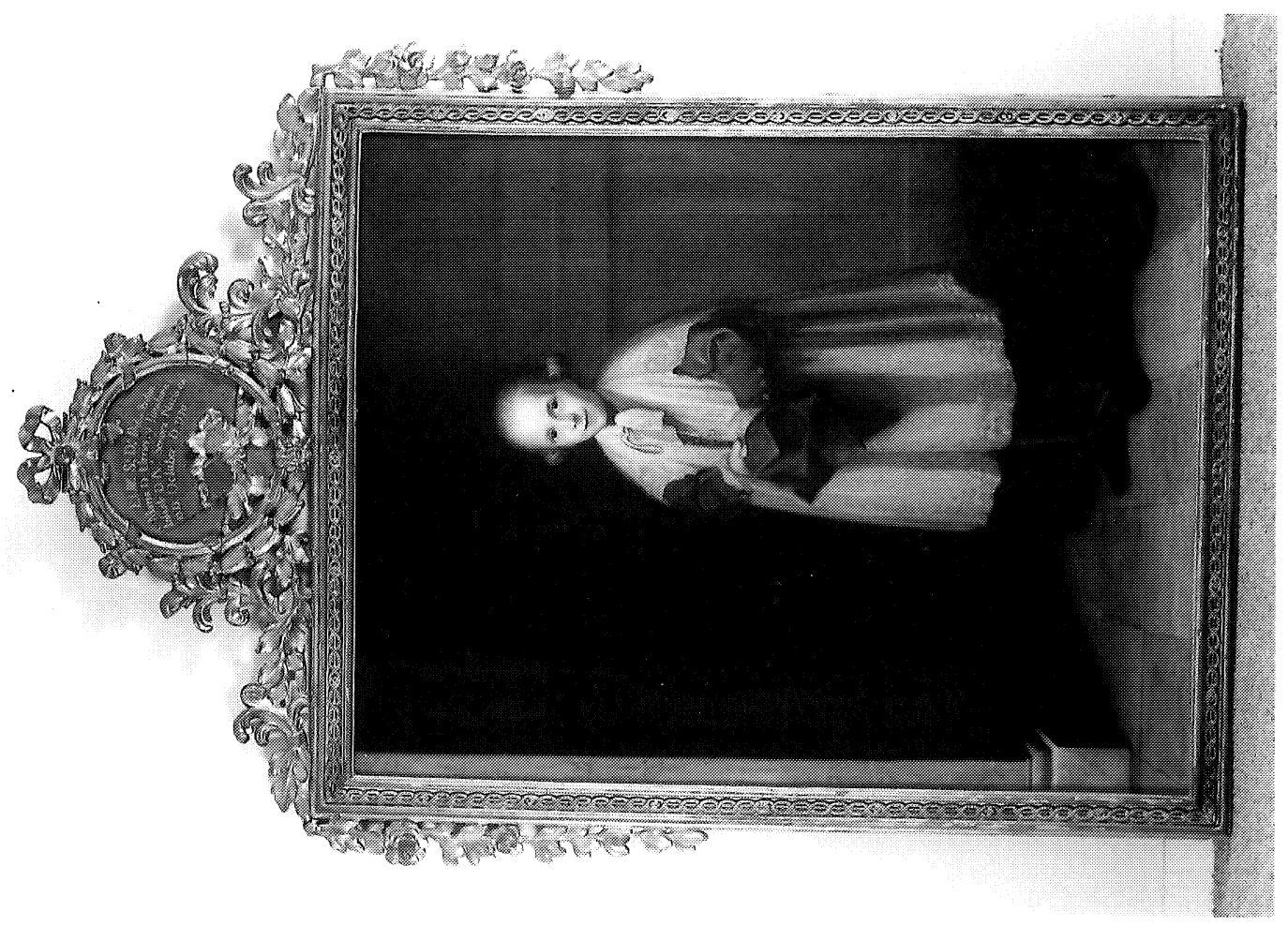

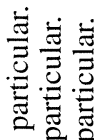
8ं 章望 冡要要 20 55 $8 \approx$ $\approx$.

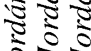
s. 골 $\approx \approx \approx$ \& 8 논 $\approx 2$ $a \div=$ $\sin$ 
rosidad, pues fueron ciertamente regias. Fue asesinado junto con José María Wanestron el 1 de Octubre de 1810 cerca del navarro pueblo de Lerín por dos guerrilleros o soldados de caballería ${ }^{23}$. Su cadáver fue reconocido por su tío político el General Palafox y por su hijo primogénito Pedro Ignacio. Como se ve tanto por los entronques de su familia como por esta misma, se trata de un personaje absolutamente significado no ya solo en Aragón, sino en toda la oscura política fernandina.

Tal era el «Infante de $\mathrm{N}^{\text {a }} \mathrm{Sr}^{\mathrm{a}}$ del Pilar» que vemos en el retrato. Quien fuera su autor no parece demasiado difícil de desentrañar. Nacido según la inscripción en el marco y según su partida de bautismo en octubre de $1770^{24}$ y partiendo de la edad con que aparece retratado, 6 u 8 años, el cuadro hubo de realizarse en los entornos de 1776 y 1778.

En el acta de su partición testamentaria, se hace constar por su nieto Juan Nepomuceno Jordán de Urríes, que entre los más de cien cuadros de su propiedad existían «catorce diferentes cuadros pintados al olio de los antecesores de la casa de S.E. incluidos los de los dos últimos Señores». Estos dos eran uno el del propio Dn. Pedro Jordán de Urríes y Fontbona y el otro el de su hijo Dn. Pedro Ignacio Jordán de Urríes y Palafox, sin que en los numerosos documentos e inventarios consultados se especifiquen sus autores, al igual que ocurre con el resto del centenar de los otros cuadros de los que ni siquiera se reseñan sus temas y que se valoran todos ellos en cantidades puramente simbólicas ${ }^{25}$.

Descartados algunos de los artistas aragoneses residentes en Zaragoza a los que la calidad del retrato y la prominencia y alcurnia de la familia del primogénito retratado excluyen terminantemente, nombres como los de Luzán (1710-1785) o Merklein (fallecido en 1792) ya fuera de moda o los de otros más jóvenes que por sus modestas dotes no pueden en sano criterio ser tenidos en cuenta como posibles autores de este magnífico retrato. Por poner un solo ejemplo Joaquín Inza ${ }^{26}$, de quien los suyos que conocemos no son por su calidad ni de lejos asimilables a este encantador y expresivo niño. Véanse los firmados por él, del Infante Dn. Gabriel ${ }^{27}$ (Fig. 12) en el que reproduce postura, consola e incluso columna exactamente vistas ya en el supuesto Retrato de Carlos IV siendo Príncipe de Asturias ${ }^{28}$, o el recientemente subastado de Dn. Nicolás de Llano y Ponte ${ }^{29}$ (Fig. 13). De este modo nos queda muy poco de que echar mano. Solamente del grupo Bayeu-Goya, de quienes sabemos que en 1780 estaban en Zaragoza decorando las «medias naranjas» del templo de El Pilar, cabe pensar en una obra así.

Estilísticamente, el cuadro se escapa de lo poco que nos es conocido del Francisco Bayeu retratista ${ }^{30}$. Si los de su hija Feliciana y su mujer Sebastiana tienen más brío —este último especialmente - el indudablemente suyo de Carlos IV que guarda la Academia de San Fernando está más cerca de la esmaltada técnica de Mengs, como la mayor parte de su obra más acabada, que de cualquiera otra. Y por supuesto de la que se ve en el del niño Pedro Jordán de Urríes.

Realizado este con los típicos empastes goyescos (Fig. 10) el retratado luce esa penetrante y directa mirada que capta instantáneamente la simpatía del espectador y que vemos siempre en

${ }^{23}$ Son de interesante consulta las Memorias del Marqués de Ayerbe sobre la estancia de Dn. Fernando VII en Valensay, publicadas en Zaragoza en 1893 por Juan Jordán de Urries.

${ }^{24}$ Parroquia del Pilar, 13 de octubre de 1770.

${ }^{25}$ Archivo Provincial de Protocolos, Zaragoza, Escribanía de Juan Antonio Vidal, n. ${ }^{\circ}$ 5.629, fs. 779 y ss.

${ }^{26}$ Cuya partida de nacimiento en 1736 fue dada a conocer por mí así como varias obras suyas en el catálogo de la exposición Los Pintores de la Ilustración, Madrid, 1988, págs. 191-195 y hasta entonces escasamente conocido.

${ }^{27}$ Colección Beatriz de Borbón, Madrid.

${ }^{28}$ Valverde Madrid, J.: «El pintor Joaquín Inza», en Goya, n. ${ }^{\circ} 159$, set.-oct. 1979, pág. 90 y mejor reproducido en Urrea, J.: «Un Inza recuperado por el Prado y otras noticias sobre su obra», en Boletín del Museo del Prado, tomo X, enero-diciembre 1989, fig. 1.

${ }^{29}$ Subastas Fortuny, Madrid, 29 mayo 1995, lote n. ${ }^{\circ} 30$

${ }^{30}$ Morales y Marín, J. L.: Francisco Bayeu, Zaragoza, 1995, ns.188, 189 y 210. 
12
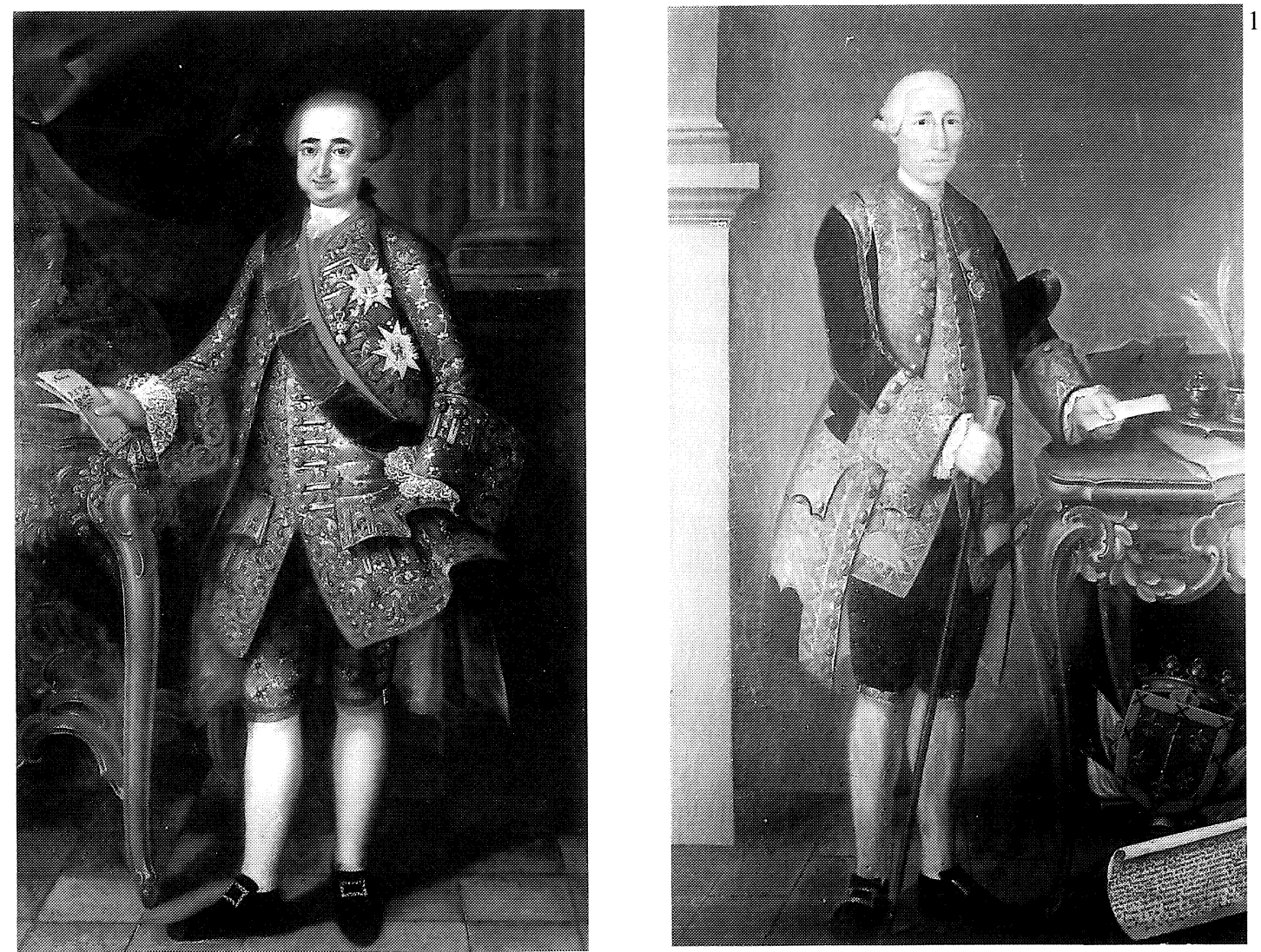

14

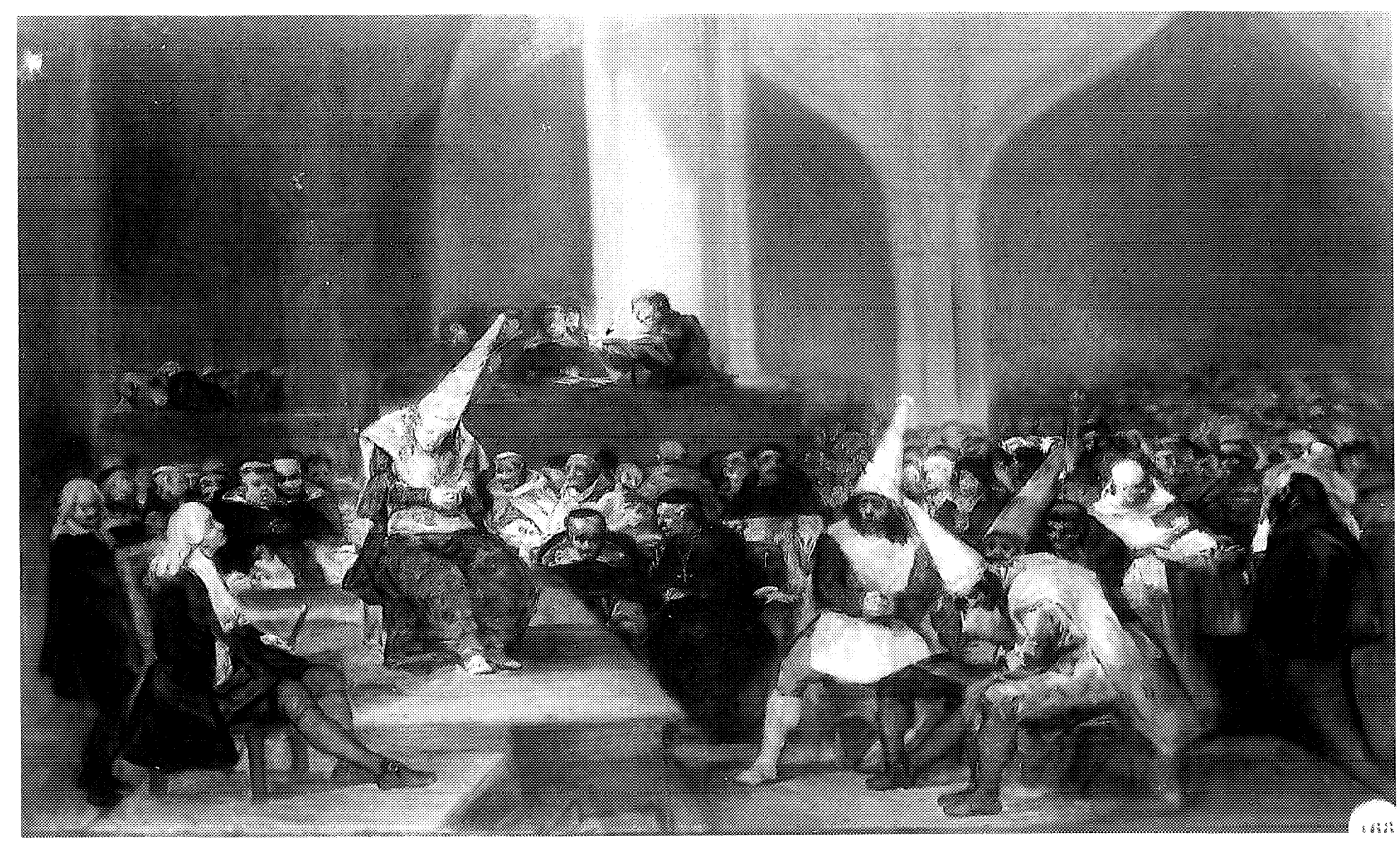

Fig. 12. Retrato del Infante D. Gabriel, por Joaquín Inza, col. Beatriz de Borbón.

Fig. 13. Retrato de D. Nicolás de Llano y Ponte, por Joaquín Inza. Madrid, Comercio.

Fig. 14. Tribunal de la Inquisición, Real Academia de Bellas Artes de San Fernando. 
los retratos infantiles del genial aragonés. Todo en él recuerda claramente a otros cuadros de Goya; desde el cuidado con que están realizados los zapatos y sus hebillas de oro, que nos hablan a las claras de la alta posición del retratado (Fig. 11), hasta el modo y manera en que aparece en un significativo segundo término la efigie de la Virgen sobre el Santo Pilar y que es claramente premonitorio de la Minerva que, años mediante acompañará a D. Melchor Gaspar y Baltasar de Jovellanos ${ }^{31}$, en su soberbio retrato atesorado por el Prado, o la abreviada forma de realizar la medalla de La Pilarica que pende sobre el pecho del futuro marqués de Ayerbe. Con todo ello creo que verdaderamente nos encontramos ante un nuevo retrato infantil de Goya que añadir a la ya conocida lista que comienza en 1783 con los de Luis María de Borbón y Vallabriga $^{32}$ — con el que el nuestro guarda fuertes semejanzas- y su hermana María Teresa, y que tras pasar entre otros por el de Manuel Osorio ${ }^{33}$, el delicioso estudio para el del Infante Francisco Pascual Antonio en la Familia de Carlos $I^{34}$, los de los Hermanos Soria ${ }^{35}$, termina con los de Pepito Costa ${ }^{36}$ y el de Víctor Guye ${ }^{37}$.

\section{Reo de la Inquisición}

Cada vez que he pasado en la Real Academia de San Fernando por delante del célebre cuadro de Goya Tribunal de la Inquisición, debo confesar que me ha sorprendido el confuso dispositivo de su fondo ${ }^{38}$ (Fig. 14). En él se ven claramente dos arcos canopiales y trepado bajo la pintura asoma a la izquierda otro medio, cuya columna desciende por detrás del hombro del acusado. Dividiendo el central, otra columna sin justificación arquitectónica alguna, recibe desde arriba una fuerte luz cuya ausencia de lógica se refuerza por una sombra que hace pensar por su proyección en un fragmento de arco de medio punto completado por la absurda sombra en cayado a su izquierda. He pensado siempre que el cuadro debió ser pintado con una gran rapidez, lo que justificaría estas vacilaciones en la composición de su fondo y los cambios o «pentimenti» efectuados en los reos y que pueden hoy percibirse a simple vista.

Pues bien, la aparición de una pequeña tabla —que por razones prácticas he titulado Reo de la Inquisición - representando la parte central y protagonista del cuadro de la Academia de San Fernando y que creo primera idea para é $1^{39}$ (Fig. 15), viene a explicar la razón de estas anomalías que acabo de comentar. La comparación de ambos cuadros pone de manifiesto que el pintor buscó intencionadamente el acusado contraste de la cabeza del escribano sobre una pared fuertemente iluminada por luz frontal. En el boceto la escena está enmarcada por un arco de lanceta, lo que permite perfectamente la partición vertical del espacio en luz y sombra, reforzando el buscado dramatismo de la composición. Es de suponer que Goya al transformar su «borrón» en una composición horizontal con muchos más personajes a derecha e izquierda, tropezó con la

\footnotetext{
${ }^{31}$ Esos eran sus nombres completos tal y como figuraron en su partida de bautismo y que se le impusieron por haber nacido el 5 de enero, víspera de la Epifanía. Por razones de utilidad, quiero pensar que no por otras, el procer ilustrado suprimió el Baltasar. G: 376, G-W: 675.

${ }^{32}$ G 149, G-W 209.

33 G 251, G-W 233.

${ }^{34}$ G 430, G-W 786.

35 G 519-518, G-W 832-833.

${ }^{36} \mathrm{G} 662, \mathrm{G}-\mathrm{W} 895$.

37 G 554, G-W 884.

38 Tribunal de la Inquisición o Escena inquisitorial: Real Academia de Bellas Artes de San Fernando (Madrid), G 462, G-W 966. Una copia por Eugenio Lucas Velázquez - Museo Municipal de Madrid, o/l 0,56×0,89— marca bien las diferencias entre ambos pintores, señaladas en Arnaiz, J. M.: Eugenio Lucas. Su vida y su obra (Madrid, 1981), p. 131. Otra copia quizá por F. Lameyer en col. Juan Giner, Madrid.

${ }^{39}$ Reo de la Inquisición, col. particular, óleo sobre tabla de forma ligeramente irregular: $0,32 \times 0,23 \mathrm{~m}$ (máximas).
} 

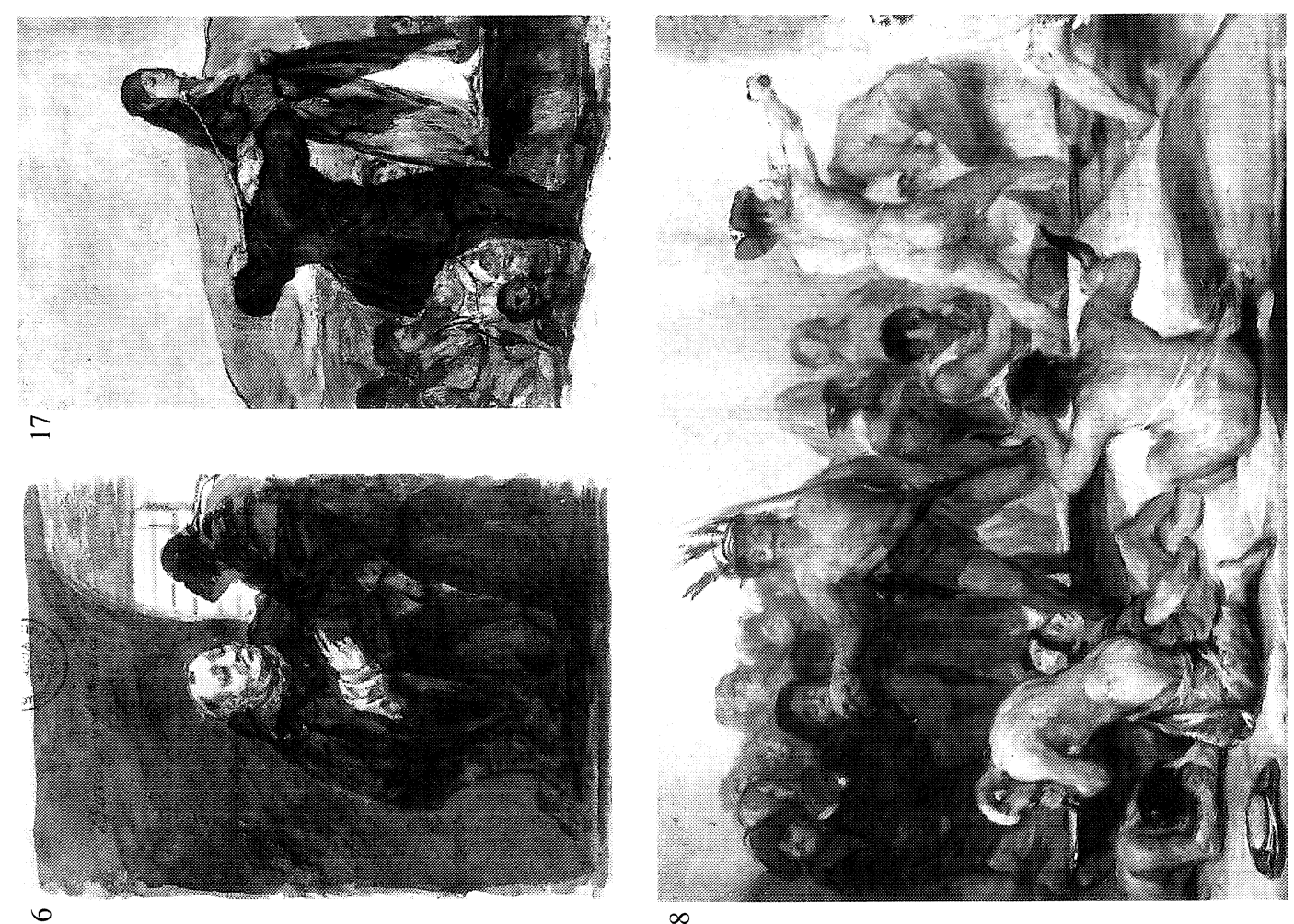

$$
\underline{0}
$$

$\stackrel{\infty}{-}$
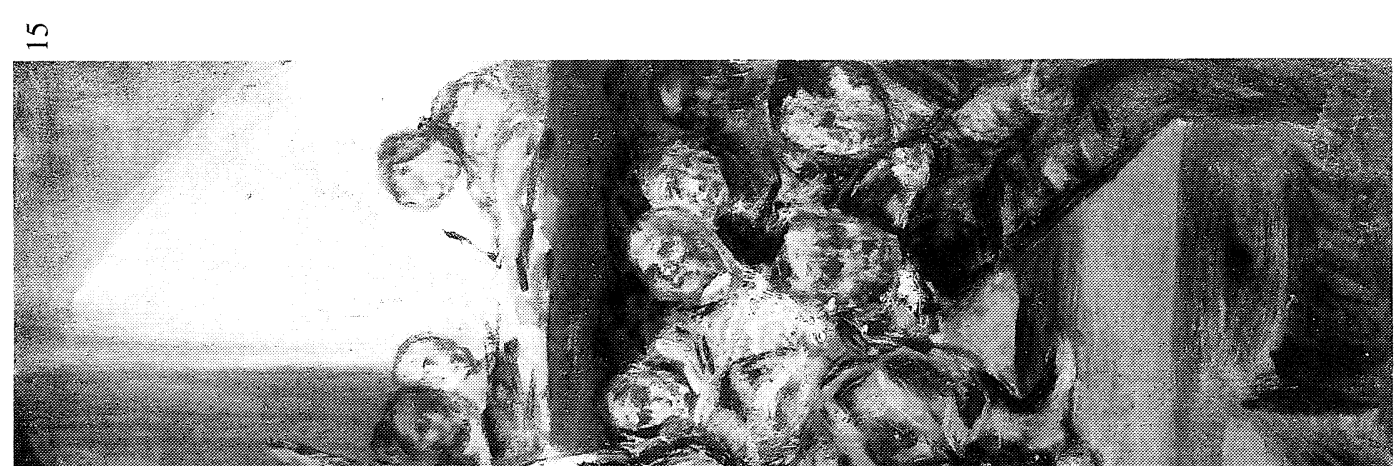

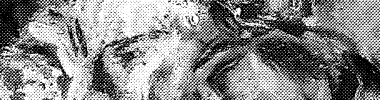

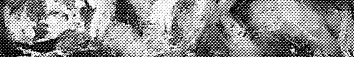

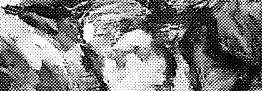

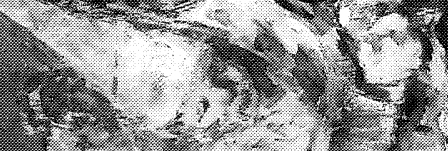
-
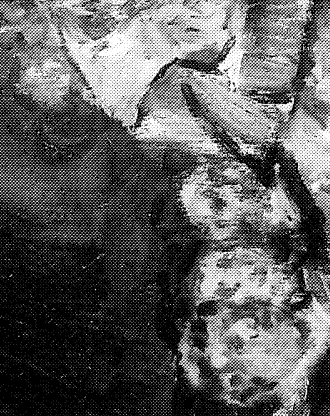

(15) 
dificultad de iluminar todo el fondo, con las alternancias de luz y sombra que le hubiera exigido una arquería. Por ello debió decidir, con la frecuente arbitrariedad que en tales casos se aprecia en sus obras, sumir en la sombra la zona más alejada, introduciendo la columna vertical y derramando sobre ella una fuerte luz directa, que si bien servía perfectamente a sus propósitos permitiéndole obtener el efecto pictórico deseado, le obligó a suprimir el arco de la izquierda. El hermoso resultado que se obtiene mediante aquella fuerte incidencia lumínica - como si procediera de un actualísimo reflector teatral - le conservó íntegramente en la composición definitiva conforme a su primera idea, pero la encuadró en forma tal que su proyección sobre la columna resulta de imposible justificación y sigue sugiriendo el arco de lanceta. De sobra es sabida la libertad con la que el pintor usó con éxito y «ad libitum» de la luz y sus efectos.

Por lo demás el traslado del boceto al fragmento central del cuadro terminado es razonablemente fiel. Si bien han variado las posturas de las cabezas, las facciones de algunos de los frailes asistentes al juicio siguen siendo reconocibles. La variante más significativa en el Tribunal de la Inquisición, que es la inclinación de la coroza del reo la corrigió, hoy visiblemente, para volver a la de la idea inicial.

Todo permite sospechar que en la tablita estamos ante un apunte rapidísimo, tomado de memoria. Esta sospecha se ve reforzada en primer lugar por la propia técnica del boceto, realizado de forma sumaria mediante el uso de tierras ligerísimas, que en muchas zonas dejan transparentar la madera del soporte de acuerdo con la conocida técnica goyesca. Las figuras están realizadas mediante un trazo fino de pincel que las contornea en negro tal y como usa el pintor en muchos de sus dibujos y tendremos ocasión de comentar más adelante. Solamente unos toques de amarillo y cuatro o cinco en rojo sobre la casulla y coroza del reo, bastan para producir el contraste y el efecto dramático deseado. La única zona donde el pigmento alcanza un cierto espesor es precisamente la iluminada que ya se ha comentado.

Este modo de hacer aproxima el Reo de la Inquisición a numerosos dibujos de Goya tanto del llamado Album $F$ como del Album $C^{40}$. Véanse por ejemplo los titulados Monjes leyendo ${ }^{41}$, Interior de Iglesia ${ }^{42}$, Gentio haciendo círculo ${ }^{43}$ o Salvajes en una cueva ${ }^{44}$, todos ellos del Album F. O los correspondientes al Album C, que llevan por título Con estos no me meto ${ }^{45}$, Por linaje de hebreos ${ }^{46}$, Ya hace mucho tiempo que somos conocidos ${ }^{47}$ y Busca un médico ${ }^{48}$ (Fig. 16), por citar solo unos pocos y claros ejemplos de los muchos que podría mencionar con la misma razón, especialmente la mayoría de los estudios preparatorios para Los disparates ${ }^{49}$. En todos ellos Goya muestra unas preocupaciones comunes: Compositivamente en el sentido de buscar el fuerte contraste luz-sombra y en su técnica por el uso del más sumario procedimiento, ejecutándolos con un firme trazo negro y aguadas. Temáticamente - y dejo aparte los que giran en torno a la Inquisición por razones obvias - se ve en todos ellos un sentimiento de desprecio y repulsión contra el clero y los religiosos, al par que

\footnotetext{
${ }^{40}$ Para los dibujos de Goya he manejado los dos volúmenes Dibujos de Goya de Pierre Gassier (Barcelona 1973-75) (en adelante «P.G. T(omo) I y T II respectivamente»). Los dibujos se identifican por la letra de su álbum y número correspondiente dentro de él en su caso y por el número correlativo de la catalogación de Gassier.

${ }^{41}$ P.G. T I: F 35, n. $^{0} 305$.

${ }^{42}$ P.G. T I: F 41, n. $^{\circ} 311$.

${ }^{43}$ P.G. T I: F 42, n. ${ }^{\circ} 312$. Ya puesto en relación con el Entierro de la sardina y Corrida de toros en un pueblo -cuadros de los que trataremos más adelante— por Salas, X. de: «Precisiones sobre Pinturas de Goya...», Archivo Español de Arte, 1965, págs. 207 a 227.

${ }^{44}$ P.G. T I: F 83, n. $^{\circ} 346$.

45 P.G. T I: C $28, n^{\circ} 176$.

${ }^{46}$ P.G. T I: C 88, n. $^{\circ} 233$.

${ }^{47}$ P.G. T I: C 119, n. ${ }^{\circ} 263$.

${ }^{48}$ P.G. T I: C 121, n. $^{\circ} 265$. Único que reproduzco por necesidades de espacio.

${ }^{49}$ P.G. T II: n. ${ }^{\circ} 290-312$, excepto 294, 303 y 311.
} 
una conmiseración por los desheredados de la fortuna y los acusados por la justicia laica o eclesiástica, al igual que el reo protagonista del boceto es visto por el pintor como la víctima compasible de una situación lastimosa.

Estas semejanzas técnicas del Reo de la Inquisición con dibujos suyos, son extensibles a algunos óleos bien conocidos. Me refiero a dos series de cuadros: la de caballete que Manuel García de la Prada donó a la Academia de San Fernando en 1839 y la compuesta por cuatro tablas en el Museo de Munich, más otras dos en Argentina y España.

La primera de ellas ${ }^{50}$ presenta definitivamente fuertes semejanzas técnicas con el Reo de la Inquisición, aparte como es natural de las temáticas con el Tribunal de la Inquisición (Fig. 14) para el cual fue primera idea. Así, analizando estructuralmente La casa de locos, vemos que tanto la figura del «indio» como el grupo de orates que le acompañan están realizados de la misma manera, con sus contornos dibujados con ese trazo negro nervioso pero firme y con idéntica forma de resolver numerosos detalles, entre ellos los ojos mediante un puntito blanco, al tiempo que utiliza la trasparencia del soporte para obtener una irisada gradación en los ocres (Fig. 18). Todo ello es también cierto para el Entierro de la sardina — donde hasta la gama de amarillos y bermellones utilizados es la misma- o para la Procesión de disciplinantes. Únicamente discrepa en cierto modo la Corrida de toros en un pueblo en cuanto a su centro protagonista aunque conservando también en el público, especialmente el que asiste desde el fondo, las mismas características.

Con la segunda de aquellas series, la compuesta por las cuatro tablas de la Neue Pinakothek de Munich Monje predicando, Ejecución de una bruja (Fig. 17), El duelo (Fig. 19) y Un herido (Fig. 20) ${ }^{51}$ a las que hay que añadir Los bandidos del Museo Castagnino ${ }^{52}$ y Carnaval $^{53} \mathrm{de}$ colección particular madrileña, las afinidades son aún mayores. Comenzando por el soporte de madera también usado en los cuadros de la Academia - y que es muy infrecuente en Goya- y continuando por el tamaño, $0,31 \times 0,21$ aprox. para la serie y $0,32 \times 0,23$ para el Reo de la Inquisición. Si a esta semejanza material unimos las técnicas, cabe pensar en una pertenencia del boceto al conjunto. Porque ciertamente los seis ya conocidos y éste están realizados de manera muy similar, con un concepto dibujístico, una alternancia entre ligerísimas aplicaciones de materia en los fondos y breves fragmentos de fuertes empastes en las zonas de interés y con una temática dramática común, notas que señalan explícitamente cuantos especialistas se ocupan de ellos.

Sobre la atribución de los cuadros de Munich recayó una sombra de duda que creo hoy suficientemente disipada, pero que conviene comentar. El catálogo de la Pinacoteca de 1963 los incluyó como apócrifos basándose en una aparente comunicación verbal hecha en 1958 a Haldor Hijas por Lafuente Ferrari, de quien se dijo que los había atribuido a Ángel Lizcano ${ }^{54}$. Pero desde 1903 en que von Loga catalogó el Monje predicando y Ejecución de una bruja cuando pertenecían a la colección Laffite en Madrid, de dónde proceden los seis, han sido acogidos por Mayer, Desparmet Fitzgerald, Gaya Nuño, Gudiol y X. de Salas sin reparo alguno ${ }^{55}$.

${ }^{50}$ Sobradamente conocida no creo necesario dar su innumerable bibliografía. Las referencias en los catálogos $\mathrm{G}$ y G-W son: La casa de locos G 464, G-W 968; El entierro de la sardina G 467, G-W 970; Procesión de disciplinantes G 463, G-W 967; Corrida de toros en un pueblo G 465, G-W 969.

${ }_{51}$ Neue Pinakothek, Erläute rungen zu den ausgestellten Werken, München, 1981, n. ${ }^{\circ} 8.615$ a 8.618. Ex colección Lafitte. —Ex col. Böhler, München, G: 732, 733, 731 y 730—. G-W: 1651 al 1654.

52 Museo J. B. Castagnino, Rosario, Argentina. Ex col. Lafitte. G: 729, G-W: 1655. Tengo noticias -no se si ciertasde que actualmente se halla en «paradero desconocido».

${ }_{53}$ Colección particular, Madrid. Ex. col. Rafael Lafora García. Ex col. Lafitte. G: 728, G-W: 1656

${ }^{54}$ Hofmann, Werner, en el catálogo de la exposición Goya. Das Zeitalter der Revolutionen. «Die Gemälde», Hamburger, Kunsthalle, 1980-81, pág. 333.

${ }_{55}$ Para unificar la bibliografía, he ordenado los cuadros en el siguiente orden: Monje predicando, Ejecución de una bruja, El duelo, Un herido, Los bandidos y Carnaval. Loga, V. von: Francisco de Goya (Berlín, 1903), n. ${ }^{\circ} 416$ y 435 Mayer, A. L.: Francisco de Goya (Barcelona-Buenos Aires, 1925), n. 526 (fig. 263), 546 (fig. 271), 616 (fig. 270 ), 615 (fig. 272). Desparmet Fitzgerald, X.: L'oeuvre peint de Goya (París, 1928-1950), n. ${ }^{\circ} 205$ (medidas invertidas) y n. 208 y 

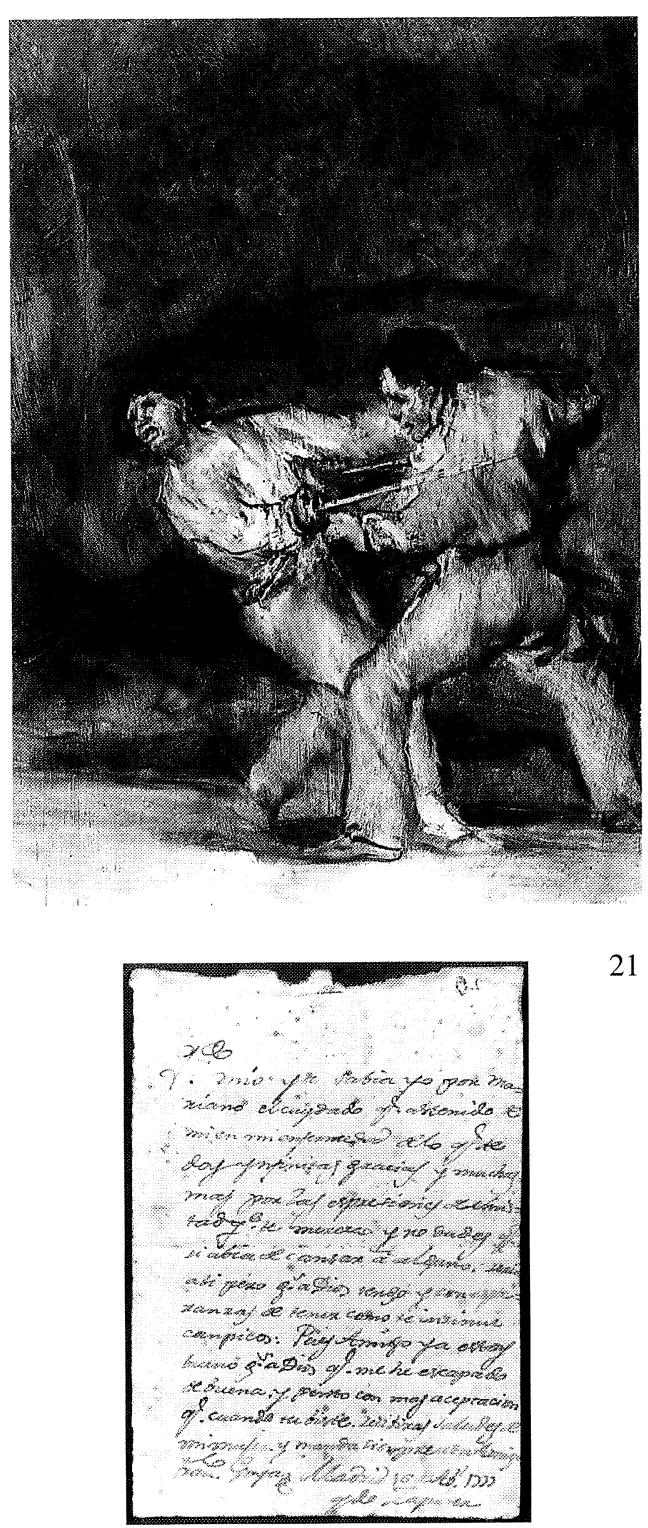

21
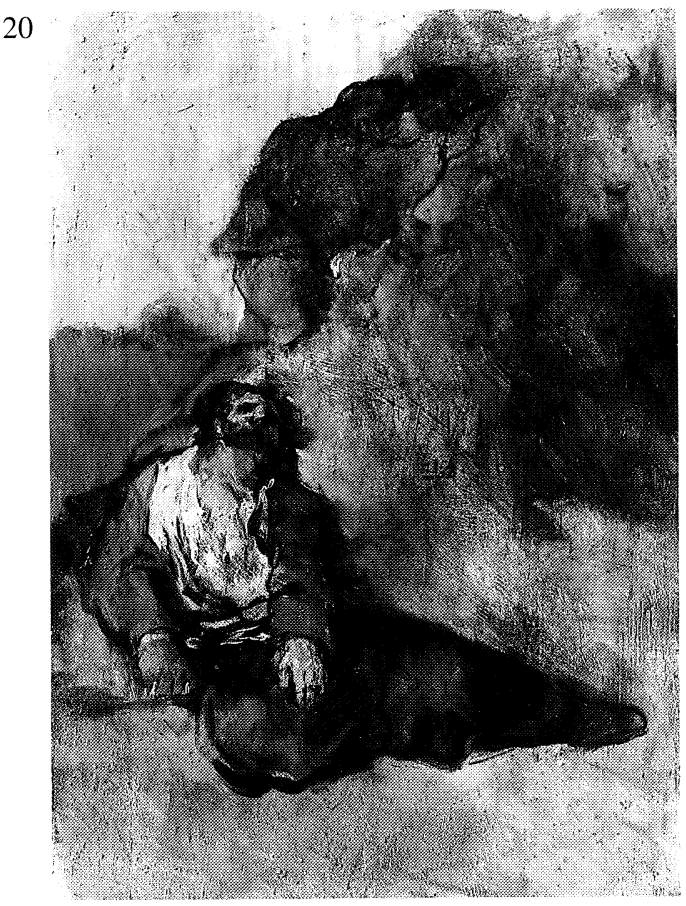

22

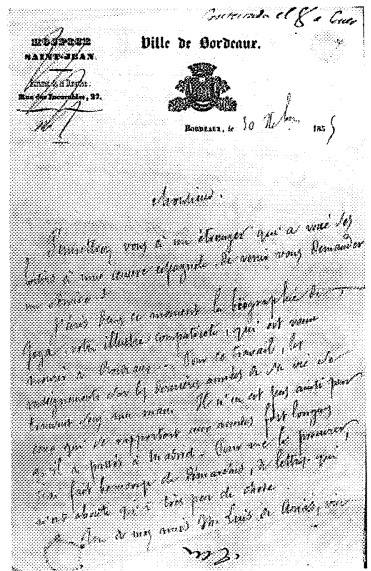

23

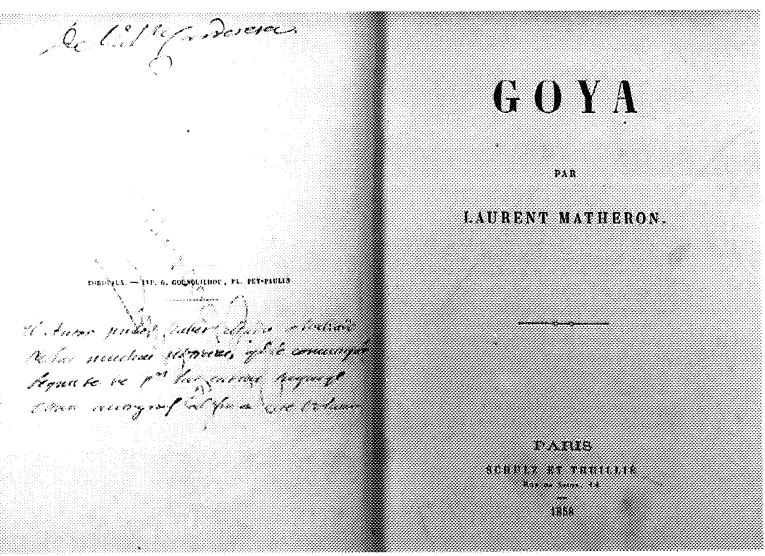

Fig. 19. El duelo. Munich. Neue Pinakothek.

Fig. 20. Un herido. Munich. Neue Pinakothek.

Fig. 21. Carta de Goya a Zapater del 16 de abril de 1777.

Fig. 22. Primera hoja de la primera carta de Matheron a Carderera.

Fig. 23. Portada del ejemplar del Matheron que fue de Vicente Carderera. 
Gudiol incluso, en su monumental obra sobre Goya - base de cuanto se ha publicado sobre el pintor aragonés, desde su edición en 1970 hasta hoy - afirma categóricamente tenerlos «como Goya seguros» ${ }^{56}$. Lo que parece confirmado por la opinión de Eberhard Ruhmer en base a los análisis de pigmentos, realizados por el sobradamente acreditado Doerner Institute ${ }^{57}$. Por su parte Gassier-Wilson (Bareau) en la nota que precede a su catálogación, mencionan su atribución discutida y su conexión con dibujos del maestro e incluso con las miniaturas que Goya hizo en Burdeos durante su exilio (lo que a mí me parece sumamente positivo) y exponen que la serie «toute entière elle mérite une étude plus approfondie» ${ }^{58}$.

Es Rita de Angelis quien tras incluirlos también en su catálogo, dice que «Es difícil determinar si estas obras corresponden a los últimos tiempos pasados en Madrid o a la estancia en Burdeos; lo que contribuye a las reservas acerca de su autenticidad, que en el caso de los n. ${ }^{\circ} .$. [los de Munich] han sido tan vigorosamente expuestas por Lafuente Ferrari (1947) como para inducir al Museo al que pertenecen a exponerlas como "apócrifas" ${ }^{59}$. Pues bien he repasado cuidadosamente la bibliografía goyesca de Lafuente y especialmente su célebre obra de 1947 Antecedentes, coincidencias e influencias del arte de Goya, sin encontrar la más leve alusión en contra de las tablas de Munich. Yo creo que las reservas manifestadas verbalmente por el respetado maestro - y sus publicaciones así lo confirman - han debido quizá limitarse al Retrato de la Reina María Luisa, propiedad también del museo muniqués y que Lafuente Ferrari atribuyó en 1947 decididamente a Ángel Lizcano ${ }^{60}$, sin mencionar para nada las tablitas en cuestión, que pertenecen al museo desde su adquisición en 1912. Lo que me lleva a pensar que el comentario de Lafuente sobre Lizcano (1846-1929, pintor costumbrista de moderado mérito) estuviese circunscrito al horrible y caricaturesco retrato de la mujer de Carlos IV $^{61}$ y quizá por un malentendido idiomático fuese extendido a estas tablas. Malentendido que pasó al catálogo de 1963 a través de Harold, provocando su inclusión como «apócrifas». Así, debe ser tenida en cuenta solo dentro de su exacto contexto, la cita de Gassier-Wilson (Bareau) ${ }^{62}$, sobre la exposición Goya and his times de 1963-1964 en la que figuraron El duelo, El herido, Ejecución de una bruja y Monje predicando y cuyo catálogo las incluye, en las fichas redactadas por Philip Troutman como: «Francisco Goya (or imitator)... Painted c. 1823-25... a series of four small paintings in the Munich Gallery (others of the series exists elsewhere), somewhat similar in style to the miniatures painted in the winter of 1824-25 (...), and probably painted in Bordeaux where Goya arrived in 1824... The attribution to Goya is not unanimous» ${ }^{63}$, titubeante y única duda sobre su autenticidad, salvo la ya explicada del

T. II, pág. 305 (repetido el n. ${ }^{\circ}$ 205). Gaya Nuño, J. A.: La pintura española fuera de España (Madrid, 1958), n. ${ }^{\circ} 972$ (medidas invertidas), 1.148, 998 y 1.147. $(\mathrm{G})=$ Gudiol, J.: Goya. 1746-1828. Biografía, estudio analítico y catálogo de sus pinturas (Barcelona, 1970), n. ${ }^{\circ} 732,733,731,730,729$ y 728. Salas, X. de: Goya, (Milán, 1978), n. ${ }^{\circ} 603$ a 608 (éste reproducido en color, pág. 161).

56 G: pág. 384.

${ }^{57}$ Hofmann, Werner: op. cit., p. 333.

${ }_{58}$ G-W. Nota a los cuadros 1651-1656, págs. 330 y 379. En esta misma parece elucidarse el problema de la supuesta atribución a Lizcano.

${ }_{59}$ Angelis, R. de: La obra pictórica completa de Goya (edición de Barcelona, 1975), p. 135.

${ }^{60}$ Lafuente Ferrari, E.: Antecedentes, coincidencias e influencias del Arte de Goya. Catálogo ilustrado de la exposición celebrada en 1932 (Madrid, 1947), p. 272. Las págs. 269 a 273, están dedicadas a una esencial crítica de la obra de Lizcano. Pero Lafuente no trata en ellas de seudo goyas, más que con referencia a un Retrato de Majo, publicado por Mayer (op. cit., n. ${ }^{\circ} 640$, fig. 71) — que nadie podría hoy seriamente suponer obra de Goya-, y cuando atribuye a Lizcano el Retrato de la Reina María Luisa (entonces como Goya en el «Katalog der älteren Pinakothek zu München», 17 Auflage, München, 1930 n. $^{\circ} 8.614$ (1480), pág. 65 , fig. 186) y que cuesta mucha imaginación suponer que incluso entonces estuviera atribuido a Goya.

${ }^{61}$ Ibidem, ilust. 73

${ }^{62}$ G-W, pág. 379.

${ }^{63}$ Troutman, Ph. y VV.AA.: Goya and his times, Winter Exhibition 1963-4, Royal Academy of Arts in London, Catalogue $3 / 6$, Third edition, n. ${ }^{\text {os }} 118-121$. 
catálogo de la Alte Pinakothek, también de 1963. Es bien sabido lo que incluso en Historia del Arte significan las modas, por efímeras que sean ${ }^{64}$.

Recientemente Bárbara Hardtwig los ha atribuido a Goya ${ }^{65}$, a cuyo nombre figuran con un texto muy explícito de Werner Hoffmann en el catálogo de la exposición Goya. Das Zeitalter der Revolutionen ${ }^{66}$ donde se presentaron Monje predicando y El duelo, al igual que en el catálogo de 1981 de la Neue Pinakothek — donde se encuentran por traspaso de la Alter- figuran las cuatro a nombre del aragonés ${ }^{67}$.

Claro está, que la postura adoptable para estos cuadros, ha de hacerse extensiva a Los bandidos del Museo Castagnino y al Carnaval de Madrid, donde según X. de Salas, en nota recogida por Gassier-Wilson ${ }^{68}$, aún existía un séptimo ejemplar de la serie cuyo sujeto y paradero exacto no se especifican y a los que por sus características técnicas, formales y temáticas - todas las composiciones están llenas de un intenso dramatismo- me siento justificado para incorporar este Reo de la Inquisición. El conjunto, por las razones aducidas es, en mi opinión, admisible como obra genuina de Francisco de Goya y Lucientes, sobre todo tras la aparición de este último cuadro, que me parece poco discutible como «borrón» para el célebre Tribunal de la Inquisición. Que el pintor realizara estudios preparatorios para la serie de la Academia, tiene ya precedente en el conocido dibujo El entierro de la sardina ${ }^{69}$ primera idea que después materializó en el óleo definitivo.

Aceptando la atribución propuesta el Reo de la Inquisición es obvio que se convierte en el nexo de unión cronológica entre las dos series de cuadros, la de la Academia y la de Munich y sus compañeros.

La datación para la de Madrid oscila grandemente. Desde c. 1800 fecha propuesta por Gudiol, al relacionarlos con los bocetos para las pinturas de la Iglesia de Monte Torrero destruidas en $1808^{70}$, hasta 1812-1819 propuesta por Gassier-Wilson al no figurar en el inventario de $1812^{71}$, lo que no parece un argumento suficientemente sólido por sí mismo. A esas fechas los atribuye X. de Salas ${ }^{72}$, en tanto que para de de Angelis, serían de 1812-1814 ${ }^{73}$.

Por contra, en las 4 pequeñas tablitas de Munich y sus compañeras, la datación es prácticamente unánime. Gassier-Wilson ${ }^{74}$, de Angelis ${ }^{75}$ y X. de Salas ${ }^{76}$ las sitúan entre 1820-1824, mientras que Gudiol que matiza algo más las considera de 1823-1824 al ser, según él «testimonio elocuente del espíritu amargado del pintor en los últimos meses que precedieron a su exilio» ${ }^{77}$.

Por otra parte, los dibujos ya citados más arriba y conexos con estos cuadros, han sido datados por Pierre Gassier en los alrededores de 1814-1824 para los del Album C ${ }^{78}$, de 1812 a 1823 para los del Album $\mathrm{F}^{79} \mathrm{y}$ finalmente los correspondientes a los Disparates o Proverbios entre 1820 y $1824^{80}$.

${ }^{64}$ Morales y Marín, en su reciente Goya. Catálogo de la pintura, Zaragoza, 1994, no las recoge.

65 Hardwig, B.: Nach Barock und Klassizismus (München, 1978), pág. 110.

66 Vid. (54).

67 Vid. (51).

68 G-W: pág. 379.

69 P.G. T. II: n. ${ }^{\circ} 21$ : El entierro de la sardina. Museo del Prado, n. ${ }^{\circ} 272$.

$70 \mathrm{G}$ : Comentario a los n. ${ }^{\text {os }} 462$ a 465 , pág. 319.

71 G-W: n. ${ }^{\text {os }} 966-970$.

72 Salas, X. de: op. cit., n. ${ }^{\text {s }} 518-522$.

73 Angelis, R. de: op. cit., n. ${ }^{\text {os }} 576-580$.

74 G-W: n. ${ }^{\text {os }} 1.651-1.656$.

75 Angelis, R. de: op. cit., n. ${ }^{\text {os }}$ 671-676.

76 Salas, X. de: op. cit., n. ${ }^{\text {os }} 603-608$.

77 G: Nota introductoria, pág. 384 a n. $.^{\text {os }} 728-733$.

78 Vid. (45) a (48).

79 Vid. (41) a (44)

80 Vid. (49). 
Yo creo que estos márgenes tan dilatados de fechas, cabe reducirlos a la vista de los nuevos hechos. Probablemente un lapso de tiempo comprendido entre 1815 y 1819 , podría suponerse con el siguiente razonamiento: Parece tan atractivo como coherente que el núcleo de los ocho dibujos del Album $\mathrm{C}$ en que Goya trata el tema de la Inquisición y que llevan números correlativos en sus inscripciones ${ }^{81}$, fueran realizados hacia Marzo de 1815 cuando precisamente el pintor fue citado el día 16 por la Cámara Secreta de la Inquisición para que explicara ante la «Santa» y su fiscal Zorrilla de Velasco si las dos Majas eran obra suya, para quien las hizo y con que fines ${ }^{82}$, fecha que sigue precisamente a la de los duros momentos que hubo de vivir el pintor bajo la presión y cuidado que le produjera la depuración política a la que había sido sometido en Noviembre de $1814^{83}$ por el inicuo Fernando VII. Preocupación quizás acrecentada por la agridulce ocasionada por el nacimiento de Rosarito Weiss el 2 de noviembre de ese $1814^{84}$, si como es casi seguro la niña era su hija ilegítima. Nada tendría pues de extraño que fuera precisamente este el momento en que su genio creador alumbrara el Reo de la Inquisición y las pequeñas tablitas, escuetas, abocetadas y que en todas sus composiciones dejan traslucir una idea como de angustiosa pesadilla, reflejo de su estado de ánimo.

Liberado ya de sus temores procedería a crear la serie de pinturas de la Academia de San Fernando. Aquí su paleta es aún luminosa y alegre. Brilla la luz en todos estos cuadros, a pesar del dramatismo, ciertamente ahora un poco burlesco, que se trasluce del Tribunal de la Inquisición, de la Procesión de disciplinantes e incluso del Entierro de la sardina. Aún no ha llegado a entenebrecerse en ellos su espléndido colorido, con esa característica forma de hacer que determina la práctica totalidad de su pintura posterior a la gravísima enfermedad que padeció en 1819 y que tiene su máxima expresión en sus Pinturas Negras, aquellas con las que decoró su villa a orillas del Manzanares ${ }^{85}$.

Así pues, creo que una fecha de c. 1815 para el Reo de la Inquisición y como consecuencia para las tablitas de Munich y sus compañeras y otra algo posterior, pero en todo caso anterior a 1819 —es decir entre 1815 y 1819 - para los cuadros de la Academia de San Fernando, encajan perfectamente no solo con la previsible actitud moral y mental de Goya, sino también estilísticamente.

Diré como colofón, que al interés que el Reo de la Inquisición tiene en sí mismo, como una de las más libres y directas realizaciones del maestro, reflejo de un momento en que su espíritu se ve turbado por una multitud de problemas - Inquisición, depuración de su actividad durante el gobierno de José Napoleón, la cuando menos aparente carencia de bienes materiales ${ }^{86}$ — hay que añadir la ayuda que supone en la clarificación del debatido tema de los cuadros de Munich y sus compañeros, además de significar un razonable punto para datar esta serie y la de los cuadros de la Academia de Bellas Artes de San Fernando.

Me parece momento oportuno para reproducir el manuscrito original de la carta de Goya a Zapater del 16 de abril de 1777, que se encuentra en colección particular y hasta ahora era conocida incluso por los eruditos únicamente por sus erróneas transcripciones ${ }^{87}$, limitándome a incluir su reproducción fotográfica (Fig. 21) despejando así cualesquiera duda.

${ }^{81}$ P.G. T I: C 85 al C 92, n. $^{\circ} 230$ al 237.

${ }^{82}$ Archivo Histórico Nacional (Madrid), Inquisición, Catálogo abreviado de Papeles de Inquisición, n. ${ }^{\circ}$ 392, publicado por Beroqui, P.: Adiciones y correcciones al catálogo del Museo del Prado (Valladolid, 1915), Parte II, pág. 89.

${ }^{83}$ Canellas, A.: op.cit. Dcts. CXXXI a CXXXIII.

${ }^{84}$ Ibidem, CXXX.

${ }^{85}$ Arnaiz, J. M.: Las Pinturas Negras de Goya, Madrid, 1996, pág. 17 et passim.

${ }^{86}$ Canellas, A.: op. cit., n. ${ }^{\circ}$ CXXIV. «Francisco de Goya... haciendo presente el estado de absoluta penuria a que se halla reducido...».

87 Ibidem: n. ${ }^{\circ}$ 14. En sus «Fuentes y Bibliografía de textos de Goya», pág. 527, respecto al documento 14, cita erróneamente a Beruete (Goya pintor de retratos, Madrid, 1916, pág. 10), error que recogen Camón (Franc ${ }^{\circ}$ de Goya, Zaragoza, 1980, pág. 91 y nota 160) y Mercedes Agueda y Xavier de Salas (Cartas a Martín Zapater, Madrid, 1982, pág. 41) en su 
Aprovecho también esta ocasión tras el retraso debido en buena parte al trabajo que me ha supuesto el Año Goya, para ampliar una somera mención en artículo mío referente a las notas manuscritas por Carderera en su ejemplar de la primera edición del Goya de Matheron y dar a conocer las dos cartas que este dirigió a Dn. Vicente ${ }^{88}$.

A raíz de su publicación en 1858, seguida nueve años más tarde por la más extensa y sin duda mejor documentada de Charles Yriarte ${ }^{89}$, comenzó una campaña de descrédito de ambas capitaneada por el sobrino de Francisco Zapater, el que fue no solo amigo íntimo del pintor sino también su corresponsal durante largos años. Con tal finalidad dio a la estampa en $1868^{90}$, el tal sobrino un pequeño opúsculo titulado Noticias biográficas, años adelante reeditado conjuntamente con 449 muy aceptables reproducciones de cuadros de Goya y enriquecido con algunas cartas dirigidas por éste a diversas personas y claro está a su tío, aunque la mayoría en extracto o parcialmente, tratando con aquellos textos partidistamente censurados por él, de dar una visión de un Goya católico, sentimental, de acendrada vida familiar. Un Goya en fin, totalmente contrapuesto, contrario y enfrentado al que ambos escritores franceses habían pintado en sus textos, pendenciero, violador de conventos, raptor de monjas, torero..., arquetipo por tanto del español que los románticos galos seudo conocedores de España habrían inventado siguiendo sus tópicos y conveniencias literarias.

Pronto surgió la controversia entre los partidarios de uno y otro Goya, rechazándose por imaginaria la de estos y como consecuencia imponiéndose finalmente la tesis de aquel, que ha perdurado en las subsiguientes biografías y estudios dedicados al pintor, hasta que bien recientemente se ha comenzado a revisar ante hechos y documentos que parece que van señalando su viabilidad, como ya tuve ocasión de advertir hace algunos años ${ }^{91}$.

Una prueba del interés mostrado por Matheron en recabar cuantos datos fueran posibles sobre la vida y la obra de Goya son las dos cartas dirigidas a Carderera y que este conservó en su ejemplar de la biografía del francés ${ }^{92}$ en cuya primera página dejó constancia manuscrita de ser su propietario («De $\mathrm{Val}^{\mathrm{n}}$. Carderera» inscripción autógrafa que precede a un párrafo en el que dice que «El Autor pudo haber citado o hablado de las muchas noticias $\mathrm{q}^{\mathrm{e}}$ le comuniqué según se ve $\mathrm{p}^{\mathrm{r}}$. las cartas suyas $\mathrm{q}^{\mathrm{e}}$ están autógrafas al final de este volumen» (Fig. 23). Ciertamente y es dato de gran importancia que Carderera se preocupó seriamente de la biografía de Goya, como demuestran sus conocidos artículos sobre el pintor, hasta el punto de que en un legajo de más de 300 hojas y papeles sueltos con noticias originales la mayoría sobre artistas españoles que a su muerte legó a la Real Academia de San Fernando, entre ellos se encontraron numerosos datos sobre Goya, de los que por cierto debió servirse el Conde de la Viñaza para su libro sobre nuestro pintor ${ }^{93}$ lo que explicaría tal vez la precoz erudición del Conde, que nacido en Zaragoza el 3

lectura de la carta. Por su parte Zapater Gómez transcribió con numerosísimos errores solamente ocho de sus líneas en Goya. Noticias Biográficas, Zaragoza, 1868, pág. 13 y G-W transcriben media línea (pág. 22). La bibliografía correcta es la que Canellas cita como propia de su documento 15 , aunque luego no se encuentre la procedencia en su «Clave bibliográfica». Lo cierto es que el original de esta carta y su lectura descifrada fue reproducido por su entonces propietario Francisco Belda y Pérez de Nueros, Marqués de Cabra, en su libro Papeles Viejos, s/l. ni f., págs. 30 y 31, sin que desde entonces y hasta ahora se haya leído en lo que yo creo, correctamente. De ahí el interés de esta reproducción puesto que la carta nos da noticia de la primera enfermedad grave de Goya.

${ }^{88}$ Matheron, L.: Goya, París, 1858. La cita en cuestión se encuentra en el artículo introductorio a la exposición Todo sobre Goya, Caja de Madrid, abril 1966, «Panorama bibliográfico de Goya», págs. 1. ㄹ 2 2. .

${ }^{89}$ Yriarte, Ch.: Goya, París, 1867.

${ }^{90}$ Zapater Gómez, F.: op. cit., vid. nota 87.

${ }_{91}$ Vid. nota 18, Ansón, op. cit. y Arnaiz, nota 17.Por su parte ya Lafuente Ferrari reconocía en 1947 que «las tradiciones recogidas por Matheron... tienen más valor de lo que suele reconocerse...»,op. cit., pág. 317, vid. nota 60.

${ }_{92}$ Tal ejemplar es o fue propiedad de Dn. Apolinar Moreno Borondo, quien generosamente me permitió su examen y autorizó a tomar las fotografías que aquí se reproducen que con las de las demás hojas obran en mi archivo.

${ }^{93}$ Viñaza, conde de la: Goya. Su tiempo, su vida, sus obras, Madrid, 1887. 
de octubre de 1862, a sus 24 años escribió el Goya (editado en 1887) y dos años más tarde en 1889 inició la publicación de sus Adiciones al célebre y aún hoy utilísimo Diccionario de Cean Bermúdez.

Reproduzco también la primera hoja de la primera de las dos cartas de Matheron (Fig. 22) y transcribo sus textos en traducción literal aunque como es natural respetando el sentido de los originales.

PRIMERA CARTA DE MATHERON A CARDERERA contestada el 8 de enero (con letra de Carderera).

HOSPICE SAINT-JEAN. Bureaux de la Direction. Rue des Incurables, 27 (Escudo de Burdeos). Ville de Bordeaux / Burdeos, 30 Noviembre 1855

Señor: / Permita usted a un extranjero que ha dedicado sus ocios a una obra española venir a pedirle un favor. / Escribo en este momento la biografía de Goya, vuestro ilustre compatriota, que vino a morir a Burdeos. Para este trabajo tengo a mano las informaciones sobre los últimos años de su vida. No es así en cuanto a los que se refieren a los muy largos años que pasó en Madrid. Para procurármelos he hecho muchas gestiones, cartas que no han dado mas que muy poca cosa. / Uno de mis amigos el Sr. Luis de Arias vicecónsul de España en Burdeos, ha sabido que usted ha conocido a Goya, que usted le apreciaba y poseía alguna de sus obras. No he dudado en escribirle seguro de antemano que en su calidad de amigo de tan gran artista, excusaría mi osadía y que además usted querría ayudarme a arrancar del olvido un nombre no demasiado conocido de los franceses. / He aquí en que consiste el servicio que me tomo la libertad de pedirle: responder a las siguientes preguntas: / 1. ${ }^{\circ}$ Podría conseguirse en Madrid un catálogo de las obras de Goya. / 2. ${ }^{\circ}$ A falta de tal relación, tendría usted la bondad de indicarme los títulos de las obras de Goya que son poco conocidas, distintas de las que se encuentran en los Museos de Madrid. Algunas palabras descriptivas o de apreciación sobre estas obras me serían también muy útiles. / 3. ${ }^{\circ}$ Podría saber en que época ha grabado Goya $1 .^{\circ}$ Los caprichos, $2 .^{\circ}$ Las corridas de toros, $3 .^{\circ}$ Las escenas de invasión, $4 .^{\circ}$ Los otros grabados. $/ 4 .^{\circ}$ Yo no conozco más que 20 planchas de las escenas de invasión. ¿Existirá un número mayor? Se estaría tentado a creerlo según el número que se encuentra en algunas planchas. / 5. ${ }^{\circ}$ Goya ha hecho litografías en Madrid? /.$^{\circ}$ Todo lo asombroso que se cuenta sobre los procedimientos empleados por Goya en su pintura, ¿es cierto? $/ 7 .^{\circ}$ ¿Conoce usted al hijo y al nieto de Goya? Podría usted pedirle para su uso en una obra escrita para gloria de su padre, y rogarle me proporcionara algunas aclaraciones. El podría hacerlo mejor que nadie. Además el podría evitarme cometer errores sobre muchos puntos. / Me limito a estas preguntas, Señor. Pero añadiré que cuanto pudiera decirme sobre su célebre amigo, será recibido con el más vivo reconocimiento. / No puedo tener éxito más que a condición de que los hombres cultos quieran dejarme aprovechar sus luces. / Le repito al finalizar, Señor, si usted se digna acoger favorablemente mi petición y honrarme con una respuesta, que usted me rendirá un gran servicio, al mismo tiempo que me proporcionará los medios para popularizar aquí la reputación de Goya. / Por cuanto usted haga, Señor, sírvase recibir todo mi agradecimiento al mismo tiempo que la seguridad de mi consideración y mi respeto. / Laurent Matheron / Homme de lettres - 102 Cours d'Aquitaine a Bordeaux / P.S. Si usted lo prefiere puede escribirme a casa del Sr. Cónsul de España en Burdeos, Sr. Carlo Navarro, del que tengo el honor de ser conocido. / Mi biografía debe aparecer hacia finales de enero, una pronta respuesta aumentaría mi gratitud.

\section{SEGUNDA CARTA, sin fecha pero anterior a 1858.}

Señor: / Le estoy muy agradecido por la rapidez que ha puesto usted en responderme. En circunstancias semejantes una exactitud tan grande bastaría para descubrir un hombre sociable y un artista de mérito: Los hombres mal educados no se toman el trabajo de responder a las cartas que se les escriben; los artistas mediocres no se preocupan de la reputación de sus antecesores. / No quisiera abusar de su excelente disposición 
pero usted me ha despertado producido los mayores deseos de leer sus artículos sobre Goya ${ }^{94}$. Tendría usted la bondad de buscarlos y comunicármelos o al menos sus copias? La lectura me sería tan útil que yo retrasaría, por esperarlos, la publicación de mi libro. / Le quedaría muy muy obligado, si usted pudiera enviar por uno de sus alumnos el catálogo sucinto de lo que usted posee de Goya. Pero yo tendría interés sobre todo en completar el catalogo de las Series de la Invasión Francesa. No he visto en París y registrado mas que 20 planchas de esta colección y usted me ha indicado que existen ; 80 u 85 ! ¿Como es posible que no exista mas que un ejemplar de esta obra? / Me haría mil veces dichoso, Señor, si usted quisiera conceder todavía alguna benevolencia a un extranjero que, a falta de no tener nada mejor, se encomienda a usted para el fin de sus esfuerzos. Todo lo que usted me envíe para mi biografía o para mi Catalogo será acogido y recogido con la mas viva gratitud. Hago votos para que usted me pida algún servicio a cambio de los que usted me rinde. Me encontrará enteramente a sus ordenes. / Reciba, Señor, mi agradecimiento y la expresión de mi respetuosa simpatía. / Laurent Matheron. Burdeos 102, Cours d'Aquitaine.

Laurent Matheron (La Réole 1823-Burdeos 1905) burócrata en el Ayuntamiento de Burdeos, fue corresponsal allí de varios periódicos y tras opositar a Oficial de la Salud fue nombrado en 1849 Director del Hospital Municipal de Saint Jean cuyo papel, como hemos visto, utilizó en su primera carta a Carderera y probablemente fragmentado al cortar el membrete también en la segunda. Su interés por precisar la biografía de Goya, sobre su obra pictórica y grabada, sobre su entorno familiar, por todo cuanto atañera al pintor queda claro no solo por el contenido de estas cartas suyas a Carderera, sino también por la mención que en su biografía hace de sus indagaciones cerca de cuantos conocieron al maestro, caso claro en su nota sobre las noticias recabadas de Brugada ${ }^{95}$, el que fue fiel acompañante de Goya y en cuyos brazos expiro el genio ${ }^{96} \mathrm{y}$ como él exiliado en Burdeos.

Bien porque las noticias enviadas por Carderera no llegaran a sus manos a tiempo o por alguna causa que ignoramos, lo cierto es que el erudito, pintor y bibliotecario, coleccionista de antigüedades y especialmente de dibujos y más concretamente de los de Goya, a quien se debe que la mayoría de ellos se salvaran de la codicia de los Madrazo ${ }^{97}$, quedó quejoso, según hemos visto, de la no inclusión de sus noticias en el librito de Matheron, quien tal vez recogiera alguna en su segundo escrito sobre el pintor ${ }^{98}$. Nada tendría de extraño que entre tales «noticias» estuviera la aún no contrastada lista de cuadros de Goya hecha por Carderera (1796-1880) que se conserva o conservaba entre sus papeles en poder de sus sucesores y que parece haber sido escrita entre 1830 y $1840^{99}$.

${ }_{94}$ Los artículos de Carderera sobre Goya, aparecidos antes de esta correspondencia son: «Biografía de D. Francisco Goya, pintor». El Artista II, 1835, págs. 253-255, y «Goya», Semanario Pintoresco, 1838, n. 120, págs. 305-308.

${ }_{95}$ Capítulo XI, nota 8: «Debemos a la exquisita amabilidad del Sr. Brugada preciosas noticias acerca de Goya y le ofrecemos aquí el testimonio de nuestro agradecimiento». Apud, 1. ${ }^{a}$ Edic. Española, Madrid, 1890, pág. 110.

${ }^{96}$ Sobre Brugada su vida y su obra existe uno magnífico estudio de Enrique Arias Anglés: Antonio de Brugada pintor romántico y liberal, Madrid, 1989.

${ }^{97}$ De las relaciones de la familia de los omnipotentes Madrazo con Xavier Goya y de su comercio con los dibujos del maestro y con sus óleos, así como de sus más que extrañas relaciones con Marianito, el nieto de Goya, ya me he ocupado en varias ocasiones, desde 1981 en mi libro sobre Eugenio Lucas y en la especialmente reciente de mi artículo dividido en dos partes «Nuevas andanzas de Goya» referentes a la exposición de Goya en el Metropolitan, Antiquaria, febrero 1996, n. ${ }^{\circ} 136$, pág. 41 y n. $^{\circ} 137$ de marzo de 1996, págs. 83-84.

${ }^{98}$ Libro de irreproducible título, que comienza Artistes contemporains des pays de Guyenne, Bearn, Saintonge et Languedoc..., Burdeos, 1889, y en el que se reproduce como ilustración de las seis páginas dedicadas a Goya (!) el aguafuerte de Flameng de Las majas al balcón en su original del Metropolitan de N.Y. Tal y como el autor declara muchos de los datos allí contenidos proceden de la obra de Yriarte, pero de Salas sospechaba que el origen de otros debía ser estudiado, (Salas, X. de: «El segundo texto de Matheron», en Archivo Español de Arte, n. ${ }^{\circ} 144,1963$, pág. 297).

${ }^{99}$ Salas, X. de: «Lista de cuadros de Goya hecha por Carderera», en Archivo de Arte y Arqueología, VII, 1931, págs. 174-178. 